\title{
Influence of Internal Curing on Properties and Performance of Cement-Based Repair Materials
}

Dale P. Bentz

Scott Z. Jones

Max A. Peltz

Paul E. Stutzman

This publication is available free of charge from: http://dx.doi.org/10.6028/NIST.IR.8076

Pre-wetted lightweight aggregates Superabsorbent polymer-coated sand (LWA)



$82 \%$ RM

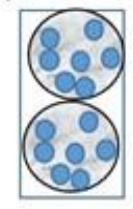

$18 \%$ LWA (pre-wetted)
(PCS)

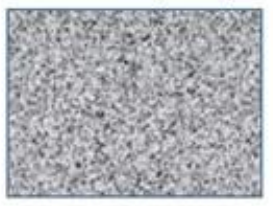

$95 \%$ RM



$5 \%$ PCS

+ water

Superabsorbent polymers

(SAP)

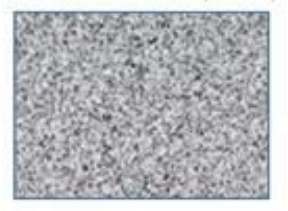

$95 \%$ RM



$5 \%$ SAP

+ water

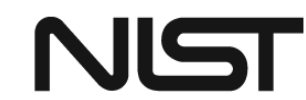

National Institute of Standards and Technology U.S. Department of Commerce 



\section{Influence of Internal Curing on Properties and Performance of Cement-Based Repair Materials}

Dale P. Bentz

Scott Z. Jones

Max A. Peltz

Paul E. Stutzman

Materials and Structural Systems Division

Engineering Laboratory

This publication is available free of charge from:

http://dx.doi.org/10.6028/NIST.IR.8076

September 2015

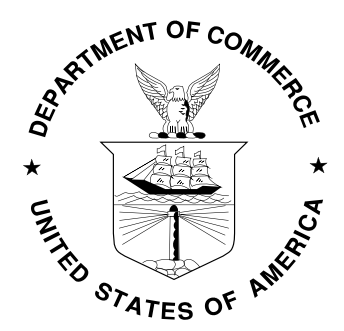

U.S. Department of Commerce

Penny Pritzker, Secretary

National Institute of Standards and Technology Willie May, Under Secretary of Commerce for Standards and Technology and Director 



\section{Abstract}

Repair materials are playing an increasingly important role in the maintenance of our nation's aging infrastructure. Understanding their properties and performance is critical to planning and executing appropriate repairs that will provide the requisite service life for critical systems and components. This study focuses on the dimensional stability of cement-based repair materials by examining the autogenous shrinkage of two representative materials, and its mitigation via the use of internal curing (IC). Three different IC agents are investigated in this regard: pre-wetted lightweight aggregates (LWA), a superabsorbent polymer-coated sand (PCS), and a superabsorbent polymer (SAP). Repair mortars with and without IC are also characterized via chemical shrinkage and setting time measurements, isothermal calorimetry, semi-adiabatic calorimetry, quantitative X-ray diffraction, and measurements of compressive strength, elastic modulus, shear slant bond, and drying shrinkage. As the IC agents have absorptions of pore solution that span two orders of magnitude, they have differing influences on mixture proportioning and subsequent performance. For the two materials investigated in the present study, the mortars using LWA to provide IC exhibited the highest compressive strengths and greatest relative reductions in autogenous shrinkage in comparison to the controls formulated without IC. Since a portion of the autogenous shrinkage in these repair mortars appears to be due to loss of internal restraint due to the dissolution of ettringite crystals (needles), the replacement of $5 \%$ of the repair mortar with a limestone powder to stabilize a portion of this ettringite and further reduce the measured autogenous shrinkage was also investigated. For this application, a coarse (16 $\mu \mathrm{m}$ median diameter) limestone powder was found to be superior to a finer $(2.2 \mu \mathrm{m})$ one in reducing autogenous shrinkage, while providing otherwise similar performance.

Keywords: Internal curing; limestone powder; lightweight aggregate; repair materials; shrinkage. 


\section{Table of Contents}

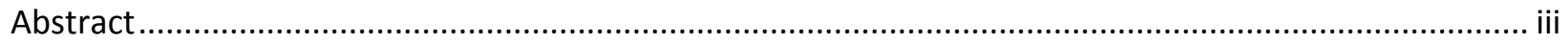

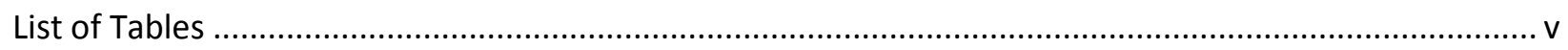

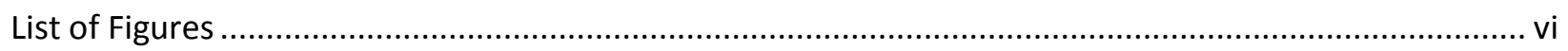



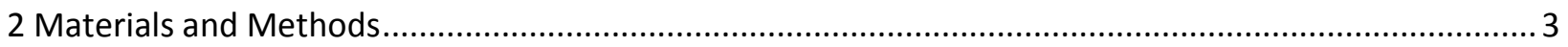

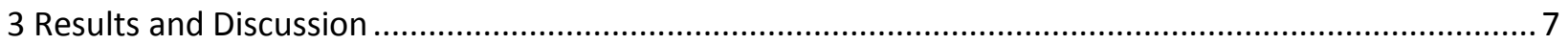

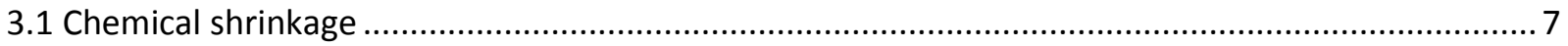

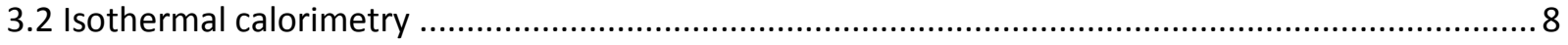

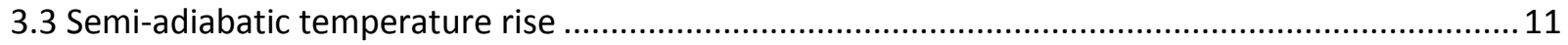

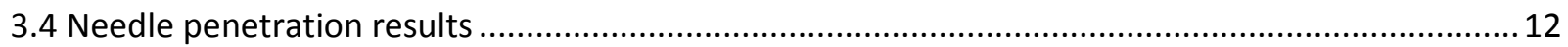

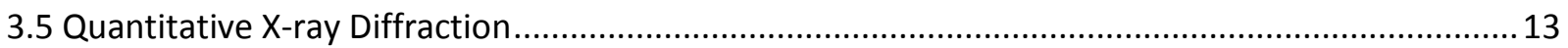



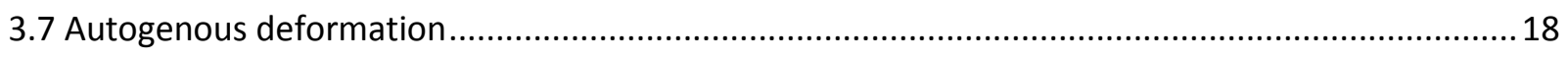

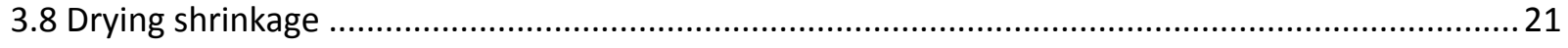

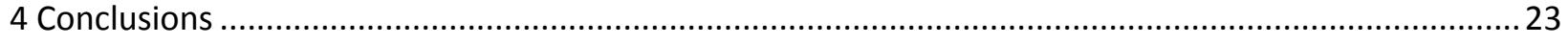

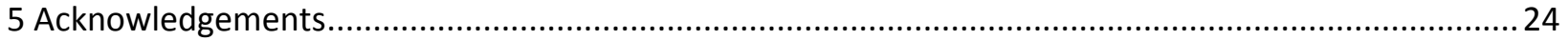






\section{List of Tables}

Table 1: Fresh and mechanical properties for repair mortars with and without internal curing. Cases where the measured values were below those provided on the manufacturers' specification sheets are highlighted

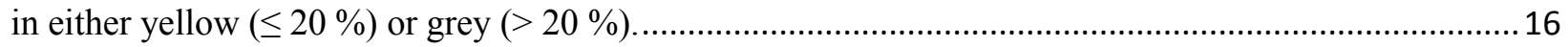

Table 2: Fresh and mechanical properties for repair mortars with limestone powder replacements in comparison to comparable mixtures without limestone..................................................................... 16

Table 3: Post-peak to $7 \mathrm{~d}$ or $28 \mathrm{~d}$ autogenous shrinkage of repair mortar mixtures with and without

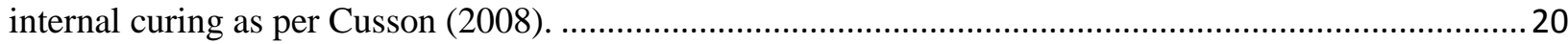

Table 4: Ultimate drying shrinkage estimated for the repair mortar mixtures with and without internal curing. 


\section{List of Figures}

Figure 1. Schematic of preparation of specimen for shear slant testing. 4

Figure 2. Illustration of repair mortar (RM) mixture proportioning (volume fractions) for IC with LWA, PCS, and SAP. Each mixture has been proportioned to provide an identical quantity of IC water per unit mass of the repair mortar.

Figure 3. Measured chemical shrinkage for the two repair mortars. Error bars indicate standard deviations for three replicate specimens.

Figure 4. Isothermal calorimetry results for heat flow for the repair mortars based on material S. Two replicate measurements (from separate half batches) are shown for most mixtures to provide an indication of measurement repeatability. 8

Figure 5. Isothermal calorimetry results for heat flow for the repair mortars based on material M. Two replicate measurements (from separate half batches) are shown for most mixtures to provide an indication of measurement repeatability......

Figure 6. Isothermal calorimetry results for cumulative heat release to $7 \mathrm{~d}$ for the repair mortars based on material S. Two replicate measurements (from separate half batches) are shown for most mixtures to provide an indication of measurement repeatability.

Figure 7. Isothermal calorimetry results for cumulative heat release to $7 \mathrm{~d}$ for the repair mortars based on material M. Two replicate measurements (from separate half batches) are shown for most mixtures to provide an indication of measurement repeatability.

Figure 8. Measured semi-adiabatic temperature rise for repair mortars S (left) and M (right). Top plots show measured data for first $48 \mathrm{~h}$ and bottom plots show data with initial mortar temperature subtracted for first $24 \mathrm{~h}$. Replicate specimens for various mortar mixtures provide an indication of measurement repeatability......

Figure 9. Needle penetration results for the various repair mortar mixtures. Dashed line indicates initial set time, according to the ASTM C191 test method (ASTM International, 2013e). Measurement uncertainty is discussed in the text above.

Figure 10. In situ X-ray diffraction measurement of phases present in repair mortar mixture S-SAP as a function of hydration time. A measure of the uncertainty is given by the variability in the counts for alite prior to the precipitation of portlandite at $5 \mathrm{~h}$.

Figure 11. In situ X-ray diffraction measurement of phases present in repair mortar mixture M-SAP as a function of hydration time. A measure of the uncertainty is given by the variability in the counts for alite prior to the precipitation of portlandite at $6.5 \mathrm{~h}$.

Figure 12. Photos of typical specimens after shear slant testing. Some strong bonding of the two materials is indicated by the deposits of one material on the opposing material face. The (darker) repair material half specimen is on the right in both images................................................................................... 17 Figure 13. Measured autogenous deformation for repair mortar mixtures based on material S. Error bars indicate \pm one standard deviation for three replicate specimens.

Figure 14. Measured autogenous deformation for repair mortar mixtures based on material M. Error bars indicate \pm one standard deviation for three replicate specimens.

Figure 15. Measured (log) drying shrinkage vs. reciprocal time for the mortars based on materials $\mathrm{S}$ (left) and $\mathrm{M}$ (right). Errors bar indicate \pm one standard deviation for six replicate specimens.

Figure 16. Measured drying shrinkage vs. measured mass loss for the mortars based on materials S (left) and $\mathrm{M}$ (right). Errors bar indicate \pm one standard deviation for six replicate specimens. 


\section{Introduction}

Every few years, the American Society of Civil Engineers issues a report card for America's infrastructure. In 2013, the most recent report card provided an overall grade of a D+, with an estimated investment of \$3.6 trillion needed by 2020 (American Society for Civil Engineers, 2013). Much of this investment will focus on repair and many dollars will be spent on repair materials that promise to restore the service life of a component or structure to its design value. In the case of repairing concrete structures and components, since most of these repair materials are applied to an existing concrete substrate, not only must one consider the performance properties of the repair material, but also its compatibility with the existing concrete (material and structure) (Morgan, 1996).

One of the key concerns regarding the performance of a cement-based repair mortar is its dimensional stability, as any expansion and/or shrinkage that the material experiences at early ages and subsequently will a) potentially produce cracking within the restrained repair material (and potentially into the existing substrate) and b) localize stresses at the repair/existing substrate interface leading to debonding and spalling. For these reasons, many cement-based repair materials are actually formulated with expansive additives to try to offset autogenous and drying shrinkage. Such an approach, however, can be less than ideal in that the expansive reactions are usually sensitive enough to temperature and humidity that it is difficult to obtain consistent results under field conditions (Bentz and Jensen, 2004). Additionally, as pointed out by Cusson (2008), it is not only the net shrinkage or expansion obtained at $7 \mathrm{~d}$ and beyond that is important, but also the pathway taken to arrive at that state. For example, an expansive agent may react quickly and produce significant expansion in the fresh state (unrestrained) and during the first few hours of hardening. Subsequent shrinkage may return the specimen to its original dimensions, but this may not be a stress-free state at all. Cusson (2008) has suggested that the shrinkage be measured relative to any expansion that occurs at early ages and not the original "cast" length of the specimen. In the fresh state, the expansion is occurring under low restraint (stress) conditions, but the subsequent shrinkage of the hardened (higher modulus) material from this expanded state can induce significant stresses and could lead to early-age cracking.

An alternative approach to reducing autogenous shrinkage (and stress development) in cement-based materials is the application of internal curing (IC) (Bentz and Weiss, 2011). In internal curing, as chemical shrinkage occurs due to the ongoing chemical reactions between the cementitious materials and water, the capillary pores within the hydrating paste that would normally empty (creating internal stresses) remain water-filled (and stress free), as water is instead removed from the larger sacrificial pores provided by the IC agent. While IC for concrete for bridge decks and other applications has been investigated extensively and reduced to practice in recent years (Bentz and Weiss, 2011; Weiss et al., 2013), the use of internal curing with repair materials has received much less attention to date. In fact, while drying shrinkage is commonly reported on manufacturer's specification sheets for repair mortars, autogenous shrinkage is rarely mentioned. De la Varga and Graybeal (2014) have considered the mitigation of autogenous shrinkage in grout-type materials (also used for repair) by supplying IC via the utilization of prewetted lightweight aggregates (LWA), observing a significant reduction in autogenous shrinkage measured via ASTM C1698 (ASTM International, 2014a) in the systems with IC. Beushausen and Gillmer (2014) have evaluated the use of superabsorbent polymers (SAP) to supply IC and reduce the cracking of bonded mortar overlays. Interestingly in their study, they chose to compare systems with and without IC at equal (total) water contents. This means that as the SAP absorbs a portion 
of the mixing water, the effective water-to-cement ratio $(w / c)$ of the paste microstructure is reduced and there will generally be a concurrent loss of workability and flow of the mortar. The alternative approach, and the one employed in the present study, is to proportion the requisite content of IC water as additional water, while maintaining the $w / c$ of the hydrating cementitious matrix. In the former approach, the reduction in effective $w / c$ will produce a denser microstructure that will offset the strength loss typically encountered in systems with IC via SAP (Beushausen and Gillmer, 2014), but may require additional chemical admixtures to match the flow behavior of the comparable system without IC. In the latter case, as $w / c$ is maintained at the same value as the reference system without IC, the flow behavior should be similar and the strength loss due to the additional (IC) water content will be partially offset at later ages by the enhanced hydration provided by the water contained in the IC agent. It is the latter approach that has been implemented for the application of IC using pre-wetted LWA in bridge deck concrete mixtures in the U.S., for example (Bentz and Weiss, 2011; Weiss et al., 2013). In the present study, the application of IC via LWA, SAP, and a polymer-coated sand are evaluated in two commercially available repair materials with respect to early-age deformation, hydration rates and setting times, and mechanical properties. 


\section{Materials and Methods}

Two commercially available repair mortars were utilized in the present study. The first, designated as material $\mathrm{S}$, is a "one-component, pre-packaged, ready-to-use, cementitious, silica fume, fiber reinforced, high strength shrinkage-compensated mortar." The second, designated as material $\mathrm{M}$, is a "one-component, shrinkage-compensated, fiber-reinforced product that contains an integral corrosion inhibitor." For the control mortars without internal curing, the mixing water was set at the middle of the manufacturers' recommended limits; for material S, this resulted in a water-to-solids ratio $(w / s)$ by mass of 0.135 , while the $w / s$ for material M was slightly less at 0.129 . It should be kept in mind that in a typical repair mortar (bag) mix, only $30 \%$ to $40 \%$ of the powder is reactive with water, suggesting a water-to-cementitious materials ratio $(w / \mathrm{cm})$ by mass on the order of 0.32 to 0.45 .

All mortars were prepared in a three-speed planetary mixer, as described in ASTM C305 (ASTM International, 2014a), with a typical batch size being based on $3600 \mathrm{~g}$ to $4000 \mathrm{~g}$ of dry repair mortar. Following the manufacturers' recommendations, the following mixing procedure was employed:

1) $80 \%$ of the mixing water was added to the mixing bowl along with the dry repair material,

2) mixing was conducted for $30 \mathrm{~s}$ on low speed,

3 ) the additional $20 \%$ of the mixing water was added during an additional $30 \mathrm{~s}$ of mixing on low speed,

4) mixing speed was changed to intermediate and an additional $30 \mathrm{~s}$ of mixing was conducted,

5) the mortar was allowed to rest for a period of $90 \mathrm{~s}$, during the first $30 \mathrm{~s}$ of which the sides of the mixing bowl were scraped down, and

6) mixing was concluded with $60 \mathrm{~s}$ of mixing on intermediate speed.

Fresh mortars were evaluated for mix temperature (range of $20{ }^{\circ} \mathrm{C}$ to $25^{\circ} \mathrm{C}$ for the eleven different mortars investigated in the present study), density via mass measurements of a filled $400 \mathrm{~mL}$ volumetric brass cup according to ASTM C185 (ASTM International, 2015), and flow using a flow table according to ASTM C1437 (ASTM International, 2013a). For a few of the mixtures, in situ X-ray diffraction (XRD) was conducted on a single specimen of the fresh mortar during the first $24 \mathrm{~h}$ of its hydration, to provide an indication of phase development at early ages. Isothermal calorimetry was measured for $7 \mathrm{~d}$ on small (about $8 \mathrm{~g}$ ) samples of mortar placed in a sealed glass vial. Semi-adiabatic calorimetry was measured for $3 \mathrm{~d}$ to $7 \mathrm{~d}$ on a mortar sample with a mass on the order of $350 \mathrm{~g}$ placed in a cylindrical plastic container surrounded on all sides by a minimum of $50 \mathrm{~mm}$ of low thermal conductivity microporous insulation (thermal conductivity, $k$ of about $0.03 \mathrm{~W} /(\mathrm{m} \cdot \mathrm{K}))$ ). A single type $\mathrm{J}$ thermocouple was used to monitor the specimen temperature within the custom-built semi-adiabatic calorimeter (Bentz and Turpin, 2007). The mortar for setting time assessment using a Vicat needle was cast in the hard rubber frustum cylindrical cone specimen mold. Three corrugated tube specimens were prepared for autogenous shrinkage, measured for $28 \mathrm{~d}$ according to ASTM C1698 (ASTM International, 2014b). Additionally, mortar cubes were cast for the evaluation of compressive strength at the ages of $1 \mathrm{~d}$, $7 \mathrm{~d}$, and $28 \mathrm{~d}$, according to ASTM C109 (ASTM International, 2013b) and six drying shrinkage prisms $(2.54 \mathrm{~cm}$ by $2.54 \mathrm{~cm}$ by $27.94 \mathrm{~cm})$ were cast for evaluation according to ASTM C596 
(ASTM International, 2009). Elastic modulus was measured using sonic (frequency) techniques according to ASTM C1259 (ASTM International, 2014c) on the drying shrinkage prisms following their $28 \mathrm{~d}$ of exposure (after cutting off both their ends to remove the metal measurement pins). To provide enough material for all of the required specimens, each mixture was prepared in two individual batches in the same morning, with the measured values for density and flow for each batch being provided in Tables 1 and 2 .

Shear slant testing (Figure 1) was conducted for five of the repair mortar mixtures. To evaluate the bonding of these repair mortars to an existing substrate, "old" mortar was first prepared using an ASTM C150 Type I/II cement (ASTM International, 2012a), $w / c=0.40$, and $55 \%$ sand by volume, and cast as one half of a shear slant specimen according to ASTM C882 (ASTM International, 2013c). After curing for at least $28 \mathrm{~d}$ in lime-water, the bonding surface of the old mortar specimen was roughened using a rotating wire brush to visually match the surface profile of an International Concrete Repair Institute (ICRI) concrete surface profile (CSP) chip \#5. Prior to the application of the repair mortar shear slant half specimen, a portion of the bottom half old mortar specimens were dried for $1 \mathrm{~d}$ at $23{ }^{\circ} \mathrm{C} \pm 1{ }^{\circ} \mathrm{C}, 50 \% \pm 3 \% \mathrm{RH}$, while the others remained in the lime-water, to compare bonding to "dry" and "wet" substrates, respectively. The completed shear slant specimens were stored in their molds at $23{ }^{\circ} \mathrm{C}$ for $1 \mathrm{~d}$ and then demolded and placed in a $23{ }^{\circ} \mathrm{C},>98 \% \mathrm{RH}$ environment until their time of testing at either $7 \mathrm{~d}$ or $35 \mathrm{~d}$. Specimens were tested in a universal testing machine in compression mode using neoprene caps. The load at failure was converted to a bond strength in MPa based on the bonding area (ellipse) of the shear slant specimen.

\section{Existing mortar Cured $\geq 28 d$}

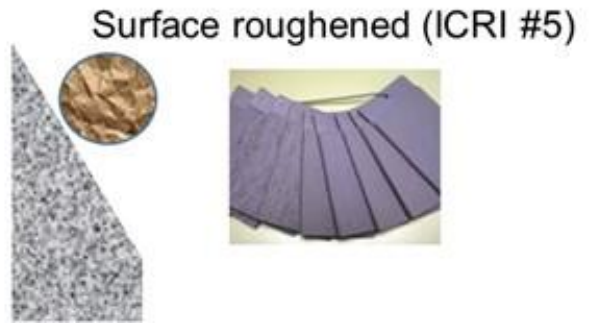

Repair mortar Cured $7 \mathrm{~d}$ or $35 \mathrm{~d}$

Figure 1. Schematic of preparation of specimen for shear slant testing.

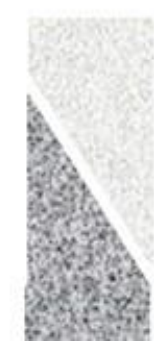

For mixture proportioning with IC, the amount of IC water needed was determined according to the procedures outlined in Bentz et al. (2005), by extrapolating experimental measurements of the $28 \mathrm{~d}$ chemical shrinkage of the two control repair mortars obtained using the ASTM C1608 standard test method (ASTM International, 2012b). For both mortars, an extrapolated value of $0.0225 \mathrm{~g}$ water/g repair mortar (dry) was employed. IC was provided by three different means to each of the two repair materials, but in each case the same quantity of IC water given above was proportioned into the mixture.

For the first IC agent, an expanded shale LWA was obtained from a manufacturer and sieved through a \#8 (2.38 mm opening) sieve to remove the coarser particles. The remaining fines were characterized with respect to their dry density $\left(1410 \mathrm{~kg} / \mathrm{m}^{3}\right)$, saturated-surface-dry density $\left(1688 \mathrm{~kg} / \mathrm{m}^{3}\right)$, absorption ( $20 \%$ by mass of dry LWA), and desorption ( $98 \%$ when exposed to a 
slurry of $\mathrm{KNO}_{3}$, with a controlled relative humidity of about $92 \%$ at $23{ }^{\circ} \mathrm{C}$ ), as per the ASTM C1761 standard specification (ASTM International, 2013d). The LWA was added to the mortar in a pre-wetted condition, after equilibrating for at least $72 \mathrm{~h}$. Mixtures for repair materials $\mathrm{S}$ and M with IC via LWA are designated as S-LWA and M-LWA, respectively.

The second means of providing IC was via the utilization of a superabsorbent polymercoated sand (PCS), commercially available and commonly employed in horticulture moisture retention and sports field moisture absorption applications. Based on information from the manufacturer and preliminary experiments, it was determined that the absorption of the PCS in a cement-based system was on the order of $2 \mathrm{~g}$ solution/g dry PCS. The PCS would have a higher absorption when placed in distilled water (12X or greater according to its manufacturer), but the value is reduced in the highly ionic, high $\mathrm{pH}$ solution that is typically found in mortars and concretes. The PCS was added to the mortar in a dry condition and the additional IC water was included as a part of the mixing water. These mixtures were designated as S-PCS and M-PCS.

The third means of supplying IC was via the use of SAP. The polyacrylate-based SAP consists of particles with an original median particle size of $60 \mu \mathrm{m}$ (as assessed using laser diffraction after immersion in isopropanol), that swell to a diameter of about $400 \mu \mathrm{m}$ (laser diffraction) when placed in distilled water. However, once again, the swelling is significantly reduced within a cement-based matrix. In this case, three-dimensional X-ray microtomography measurements and information from the manufacturer were used to determine an absorption on the order of $20 \mathrm{~g}$ solution/g SAP (dry) for this material, approximately 10 times that of the PCS and 100 times that of the LWA. The SAP was pre-mixed dry with the repair mortar (S-SAP and M-SAP) and the additional IC water was included as part of the mixing water.

The various means of supplying IC explored in this study are illustrated schematically in Figure 2. It is of interest to note that because the repair mortar is a pre-packaged material, the IC agent is added "on top" of the ordinary mixture proportions, altering the volume fraction of repair mortar in the mixtures with IC vs. the control mortars prepared without IC. This is especially noticeable for the repair mortars prepared with LWA, where $18 \%$ of the final volume is occupied by the porous but rigid LWA particles. The changes to mixture volume fractions illustrated in Figure 2 would be expected to also influence mechanical properties and autogenous shrinkage of the produced mortars.


Figure 2. Illustration of repair mortar (RM) mixture proportioning (volume fractions) for IC with LWA, PCS, and SAP. Each mixture has been proportioned to provide an identical quantity of IC water per unit mass of the repair mortar. 
In the latter stages of the study, the incorporation of limestone powder $\left(95 \% \mathrm{CaCO}_{3}\right)$ into the repair mortar mixture was investigated in a series of three mixtures. As will be presented subsequently, it was conjectured that a significant portion of the autogenous shrinkage of these repair materials is due to the dissolution of restraining ettringite crystals; it was further envisioned that limestone powder additions might mitigate a portion of this shrinkage by better stabilizing (chemically) the ettringite formed at early ages (Lothenbach et al., 2008; Zajac et al. 2014). To explore this possibility, limestone powders with NIST-measured median diameters of $2.2 \mu \mathrm{m}(1.4$ $\mu \mathrm{m}$ according to the manufacturer) and $16 \mu \mathrm{m}$ (17 $\mu \mathrm{m}$ according to the manufacturer) (Gurney et al., 2012) were used to replace $5 \%$ of the repair mortar on a mass basis. A $5 \%$ replacement was selected based on previous experience with similar limestone powder replacements in OPC and ternary (cement/fly ash/limestone) concretes (Bentz et al., 2014; Bentz et al., 2015). Both the fine and coarse limestone powders were used in separate mixtures with repair material $\mathrm{M}$ without internal curing, designated as M-fLSP and M-cLSP, respectively. Given the subsequent superior performance of the coarse limestone powder in this mixture in terms of reduced autogenous shrinkage, it was also employed in a mixture with repair material $\mathrm{S}$ and IC supplied by LWA (designated as S-LWA-cLSP). 


\section{Results and Discussion}

\subsection{Chemical shrinkage}

The measured chemical shrinkage for the two repair materials is provided in Figure 3. Based on the data trends for each of the two mortars, a conservative value of $0.0225 \mathrm{~mL}$ water per gram of repair mortar was ultimately chosen as the IC water requirement. ${ }^{1}$ This single fixed volume of IC water was supplied to the repair mortars using each of the three different IC agents.

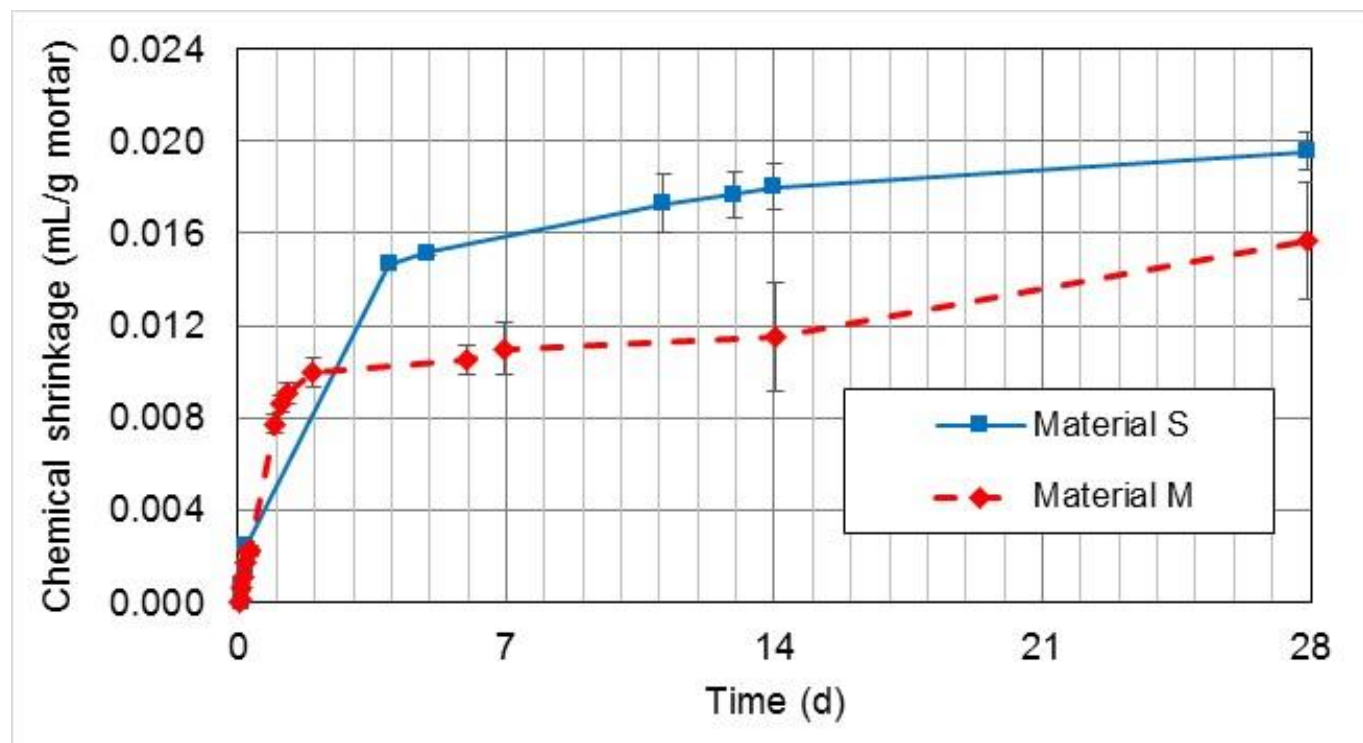

Figure 3. Measured chemical shrinkage for the two repair mortars. Error bars indicate standard deviations for three replicate specimens.

\footnotetext{
${ }^{1}$ An initial mixture of repair mortar M prepared with LWA and an IC water dosage of $0.015 \mathrm{~mL}$ water per gram of repair mortar exhibited substantial autogenous shrinkage (about -300 microstrain at $28 \mathrm{~d}$ ), indicating that the IC water was likely underdosed. That mixture (M-LWA) was repeated with an IC water quantity of $0.0225 \mathrm{~mL} / \mathrm{g}$ mortar and that quantity of IC water was also used in the subsequent PCS and SAP mixtures for material M.
} 


\subsection{Isothermal calorimetry}

The isothermal calorimetry results for the 11 mortar mixtures are provided in Figures 4 and 5 for heat flow for the first $24 \mathrm{~h}$ and in Figures 6 and 7 for cumulative heat release during the first $7 \mathrm{~d}(168 \mathrm{~h})$. In normalizing the calorimetry results for the three mixtures containing limestone powder replacement for repair material, the mass of the limestone powder was included as part of the repair mortar mass, as the water was proportioned based on this total mass and not simply on the mass of the repair material itself. In general, the repeatability in the measurements for the two half batches of mortar prepared on the same morning is quite reasonable, with the S-SAP and the M-PCS being the most notable exceptions. Still, even for these two mortar mixtures, the repeatability is sufficient to observe any acceleration or retardation effects of the IC agents.

For both repair materials, the addition of IC, via any of the three IC agents, is seen to retard the early-age hydration, shifting the primary peak to later times. The retardation is generally more severe for those IC agents based on SAP (PCS or SAP), likely due to the complexation and/or sorption of calcium ions by the polymer. ${ }^{2}$ The most severe retardation, on the order of $3 \mathrm{~h}$, was found for material $\mathrm{M}$ with IC via PCS. The heat flow from material $\mathrm{S}$ is about $50 \%$ higher than that from material $\mathrm{M}$ and occurs at an earlier time (peak time of $8 \mathrm{~h}$ to $12 \mathrm{~h}$ vs. $10 \mathrm{~h}$ to $15 \mathrm{~h}$ ), suggesting a more reactive binder and a greater concentration of reactive components in the former material. For material $\mathrm{M}$, the $5 \%$ fine limestone replacement accelerated the early-age reactions in comparison to the coarse limestone powder. For material S, a $5 \%$ coarse limestone replacement in the LWA mixture slightly accelerated its hydration, but the peak heat flow was slightly reduced due to the dilution of the reactive repair material with the less reactive limestone powder.

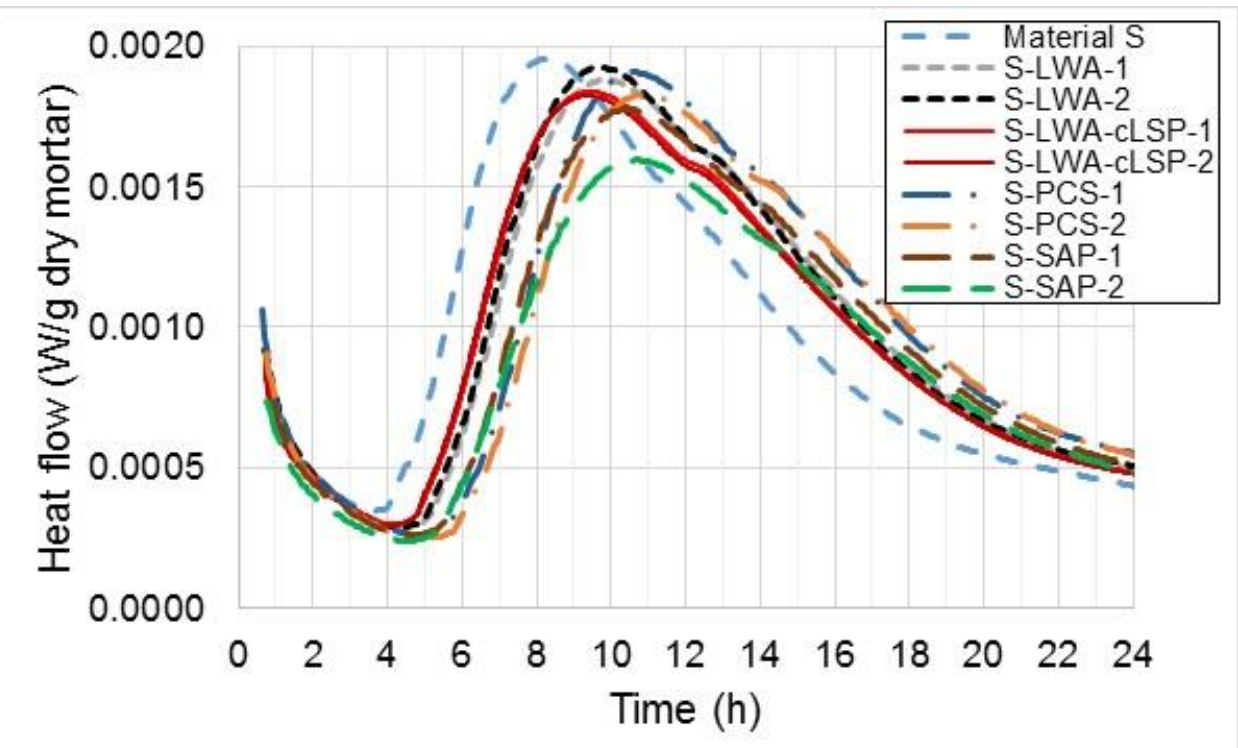

Figure 4. Isothermal calorimetry results for heat flow for the repair mortars based on material $S$. Two replicate measurements (from separate half batches) are shown for most mixtures to provide an indication of measurement repeatability.

\footnotetext{
${ }^{2}$ Although reliable quantitative analysis proved to be difficult, substantial reductions in calcium ion concentration were measured using inductively coupled plasma (ICP) analysis of saturated solutions of calcium hydroxide exposed to (filtered through) PCS or SAP particles, in comparison to minor reductions when exposed to LWA.
} 


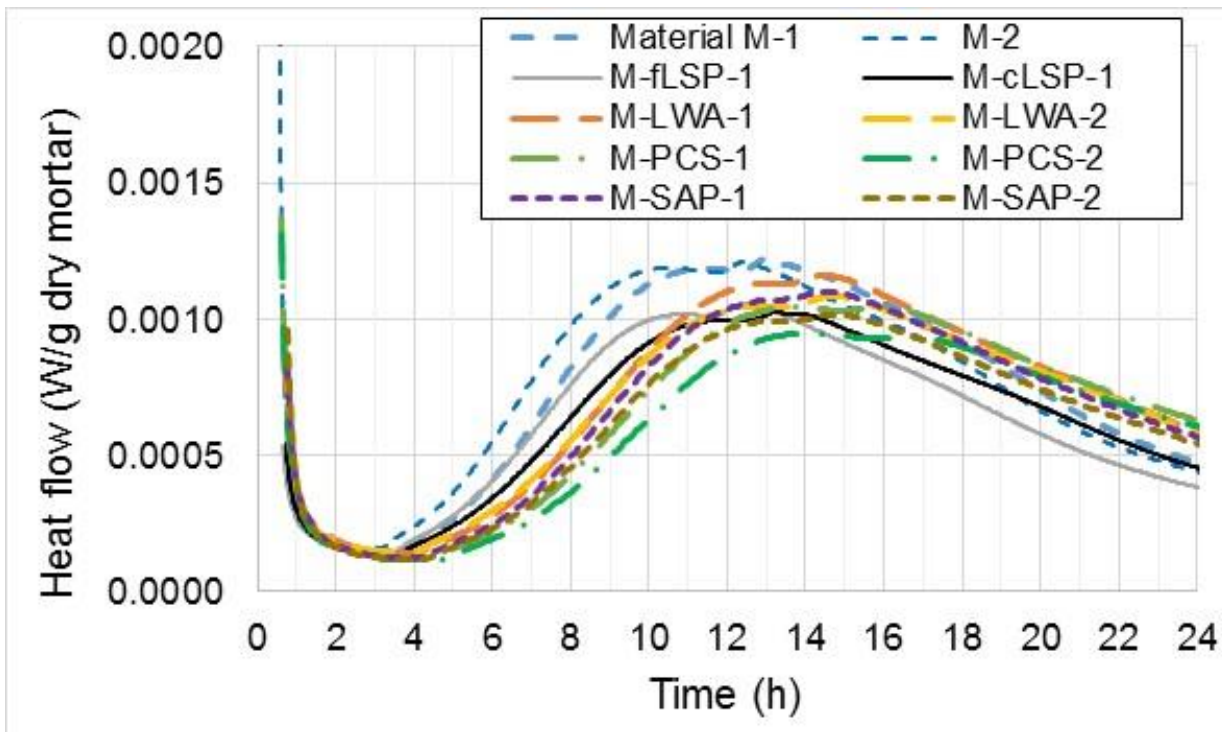

Figure 5. Isothermal calorimetry results for heat flow for the repair mortars based on material M. Two replicate measurements (from separate half batches) are shown for most mixtures to provide an indication of measurement repeatability.

The cumulative heat release curves in Figures 6 and 7 clearly indicate one of the expected benefits of IC, namely enhanced hydration at later ages due to the provision of the additional IC water. For material $\mathrm{S}$, all of the mixtures with IC produce similar values of $7 \mathrm{~d}$ heat release that are about $10 \%$ higher than that exhibited by the reference mixture without IC, with the S-SAP-2 mixture likely being an outlier. There is more dispersion among the results for material $\mathrm{M}$, with LWA and PCS providing the highest heat releases at $7 \mathrm{~d}$. The additional hydration in these mixtures with IC should contribute to strength development, helping to offset any strength reductions due to the addition of the porous IC agents to the mortar matrix (Bentz and Weiss, 2011). When considering the limestone replacements for repair mortar, their dilution of the more reactive component resulted in lower $7 \mathrm{~d}$ heat release values for material $\mathrm{M}$ in Figure 7, with the coarse limestone outperforming the fine limestone at ages of $2 \mathrm{~d}$ and beyond. When the same coarse limestone was used in material S with IC via LWA (S-LWA-cLSP), as shown in Figure 6, the cumulative heat release curves basically overlapped those obtained for the comparable mortars (S-LWA-1 and S-LWA-2) without the limestone replacement. 


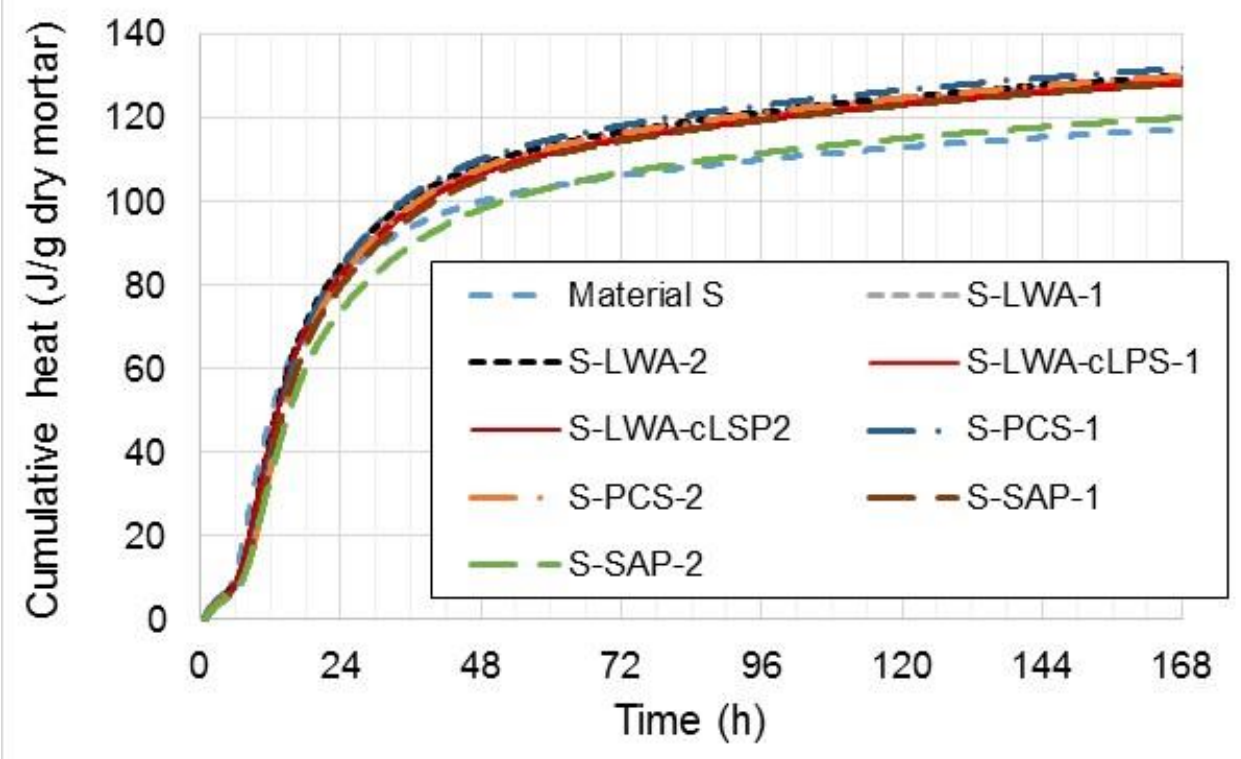

Figure 6. Isothermal calorimetry results for cumulative heat release to $7 d$ for the repair mortars based on material S. Two replicate measurements (from separate half batches) are shown for most mixtures to provide an indication of measurement repeatability.

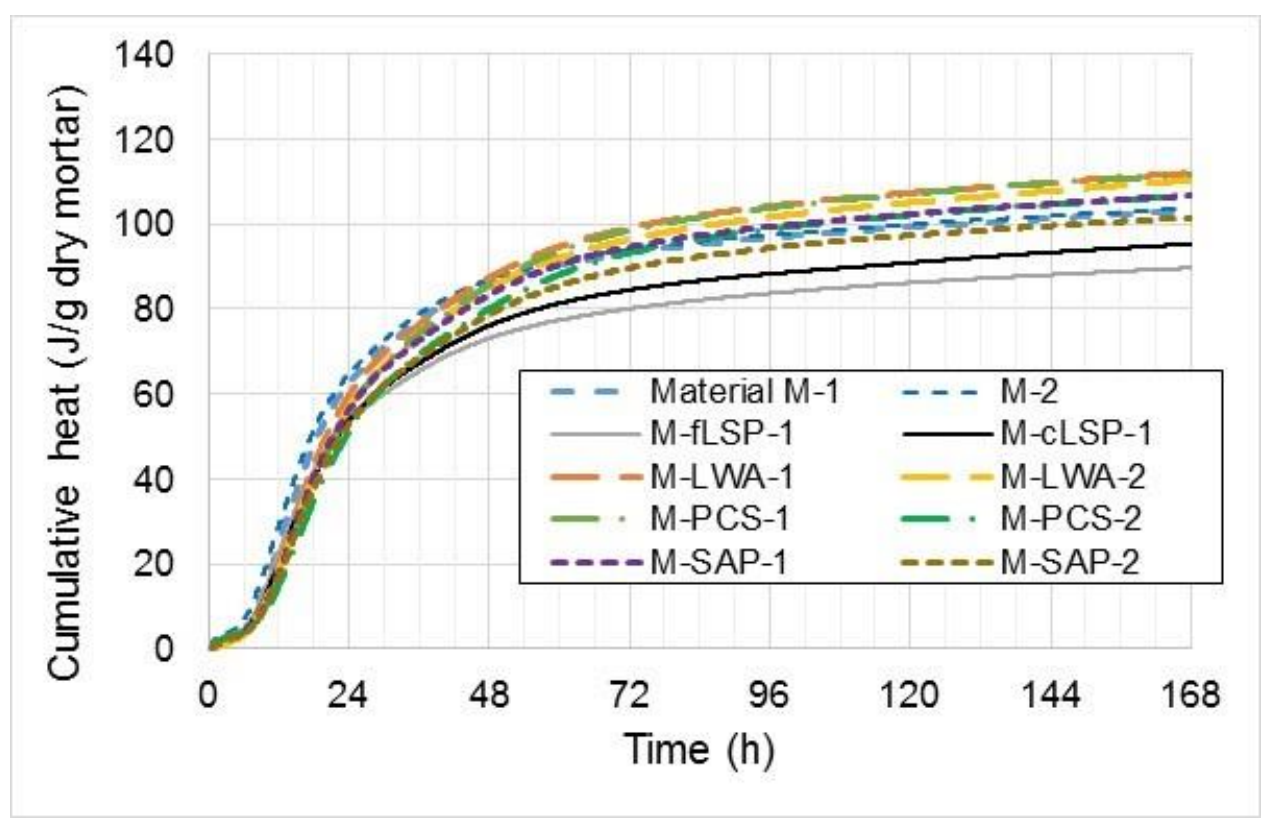

Figure 7. Isothermal calorimetry results for cumulative heat release to $7 d$ for the repair mortars based on material M. Two replicate measurements (from separate half batches) are shown for most mixtures to provide an indication of measurement repeatability. 


\subsection{Semi-adiabatic temperature rise}

The semi-adiabatic measurements of temperature rise for the 11 mortar mixtures are summarized in Figure 8 that shows both the raw data and the data corrected for the (variable) initial mixture temperature. Unlike isothermal calorimetry, the semi-adiabatic response is strongly influenced by both the reactivity and the thermal capacity of the specimen. For both materials, the highest temperature rise is measured for the mixture without IC, due to its higher volume fraction of reactive material (dilution due to IC), as well as the retardation in the mixtures with IC mentioned earlier. The maximum temperature occurs $2 \mathrm{~h}$ to $3 \mathrm{~h}$ later in mixtures containing material $\mathrm{M}$ than in those containing material $\mathrm{S}$. The greatest retardation is observed in mixture M-PCS, in agreement with the isothermal calorimetry results presented earlier.

The temperature rise is less in the M-fLSP and M-cLSP mixtures containing limestone due to the dilution of the repair material by the less reactive limestone powder. Conversely, with mixture S-LWA, the temperature rise is slightly increased and occurs at an earlier time when coarse limestone replaces $5 \%$ of the repair material. In general, there is reasonable repeatability between the two batches of a given mixture prepared sequentially on the same day.
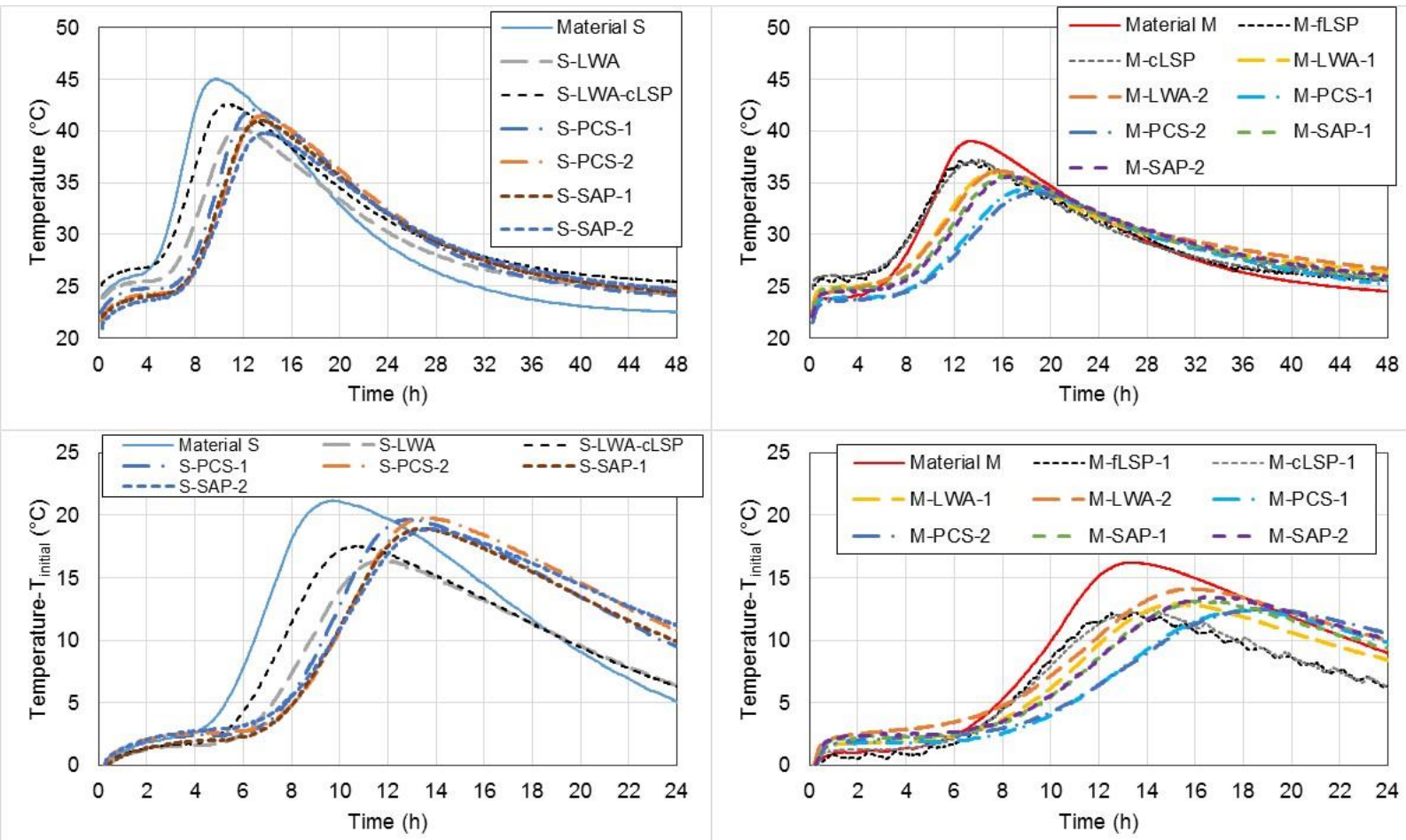

Figure 8. Measured semi-adiabatic temperature rise for repair mortars $S$ (left) and $M$ (right). Top plots show measured data for first $48 \mathrm{~h}$ and bottom plots show data with initial mortar temperature subtracted for first $24 \mathrm{~h}$. Replicate specimens for various mortar mixtures provide an indication of measurement repeatability. 


\subsection{Needle penetration results}

To assess the setting behavior of the repair mortar mixtures, needle penetration measurements using an automated Vicat apparatus were employed; ASTM C191 (ASTM International, 2013e) describes the measurement that is commonly employed on cement pastes, but in this study, it was used on mortars as well. Replicate measurements on specimens from the same prepared batch of mortar exhibited a standard deviation in initial setting time of between 3 min and 15 min. As can be seen in Figure 9, IC with LWA reduced the setting time for both repair materials, with the reduction being significantly greater for material S. Since these systems exhibited a mild retardation in the calorimetry results presented earlier, it is hypothesized that the presence of the rigid LWA particles at about an $18 \%$ volume fraction significantly stiffens the mortar so that "setting" occurs earlier. The previously mentioned retardation caused by the SAP is also observed in Figure 9, where the setting times of the S-SAP and M-SAP mixtures exceed those measured for the $S$ and $M$ materials without IC by about $1 \mathrm{~h}$. Conversely, the retardation observed in the calorimetry results for the PCS mixtures was not observed in the setting results, as S-PCS exhibited an earlier setting time than material S without IC, while M-PCS had a similar setting time to that of material $\mathrm{M}$ without IC. This will be discussed further when the quantitative X-ray diffraction results are presented in the next section of this report.

For material M, the results with the two limestone replacements for repair material (not shown in Figure 9) were within 15 min of those for the material $\mathrm{M}$ original mixture. For mixture S-LWA-cLSP, however, setting occurred 20 min later than for the comparable S-LWA mortar mixture shown in Figure 9, likely due to dilution of the reactive component.



Figure 9. Needle penetration results for the various repair mortar mixtures. Dashed line indicates initial set time, according to the ASTM C191 test method (ASTM International, 2013e). Measurement uncertainty is discussed in the text above. 


\subsection{Quantitative X-ray Diffraction}

To have a better understanding of the reactions occurring at early ages in these two cementbased materials, in situ X-ray diffraction was conducted, followed by quantitative estimates of phase abundance by diffraction peak intensity measurement. The results obtained for mixtures SSAP and M-SAP are shown in Figures 10 and 11, respectively. The changes in original phases (alite, gypsum, and anhydrite) dissolved and crystalline hydration products (ettringite and portlandite) formed with time during the first $24 \mathrm{~h}$ differ significantly from those commonly encountered for an ordinary portland cement, particularly in the amount of ettringite that is formed at early ages. Likely due to expansive agents (aluminates) added to the mortar formulations, there is a considerable quantity of ettringite that has been generated even prior to the first XRD scan 1 $\mathrm{h}$ after contact between the repair material and water. Ettringite continues to form throughout the first $24 \mathrm{~h}$, as first gypsum and then anhydrite are sequentially depleted as sulfate sources (Figures 10 and 11). The tricalcium silicate (alite) only begins to react in earnest after about $5 \mathrm{~h}(6.5 \mathrm{~h}$ in Figure 11), as supported by the concurrent generation of calcium hydroxide (portlandite), a product of alite hydration.

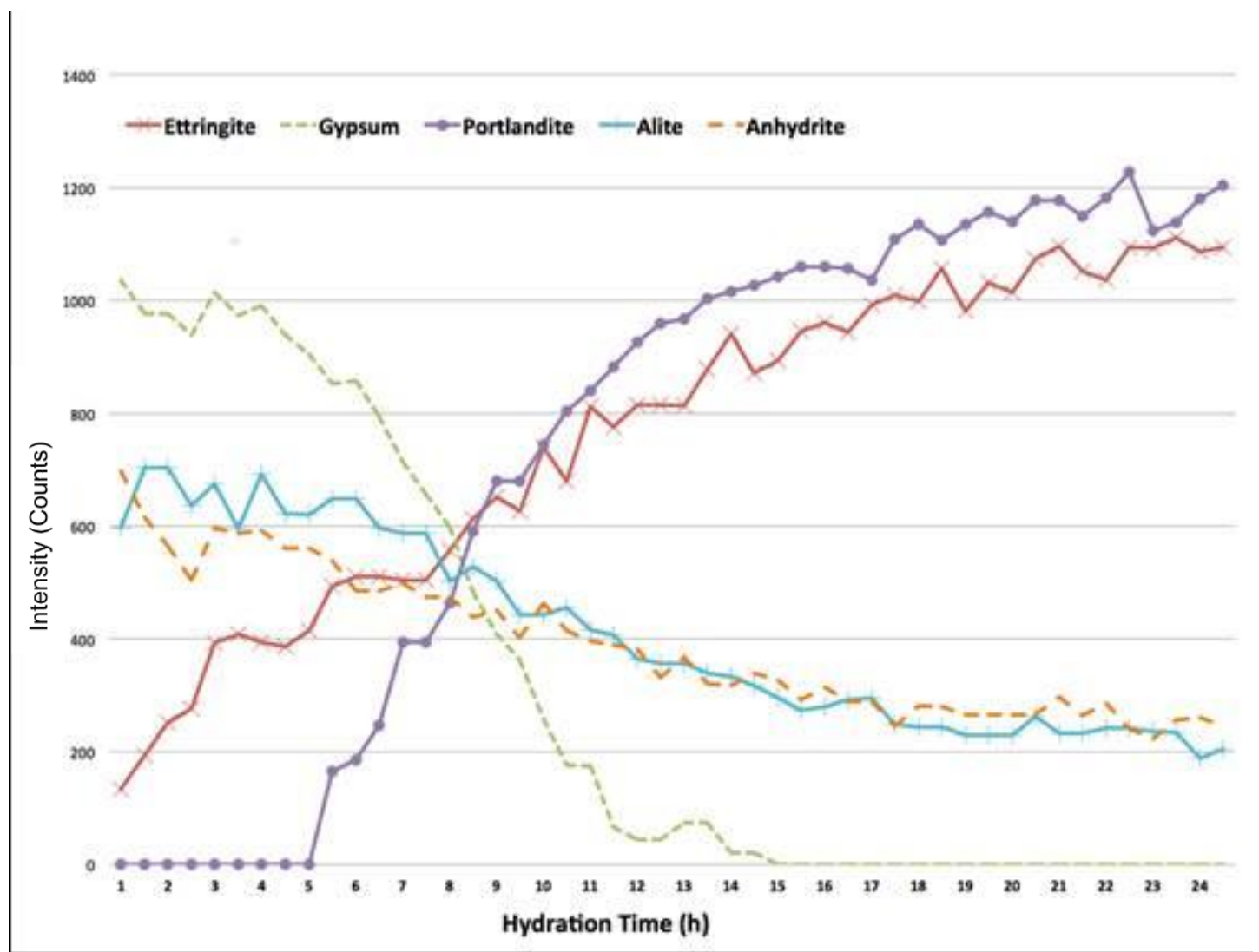

Figure 10. In situ X-ray diffraction measurement of phases present in repair mortar mixture S-SAP as a function of hydration time. A measure of the uncertainty is given by the variability in the counts for alite prior to the precipitation of portlandite at $5 \mathrm{~h}$. 


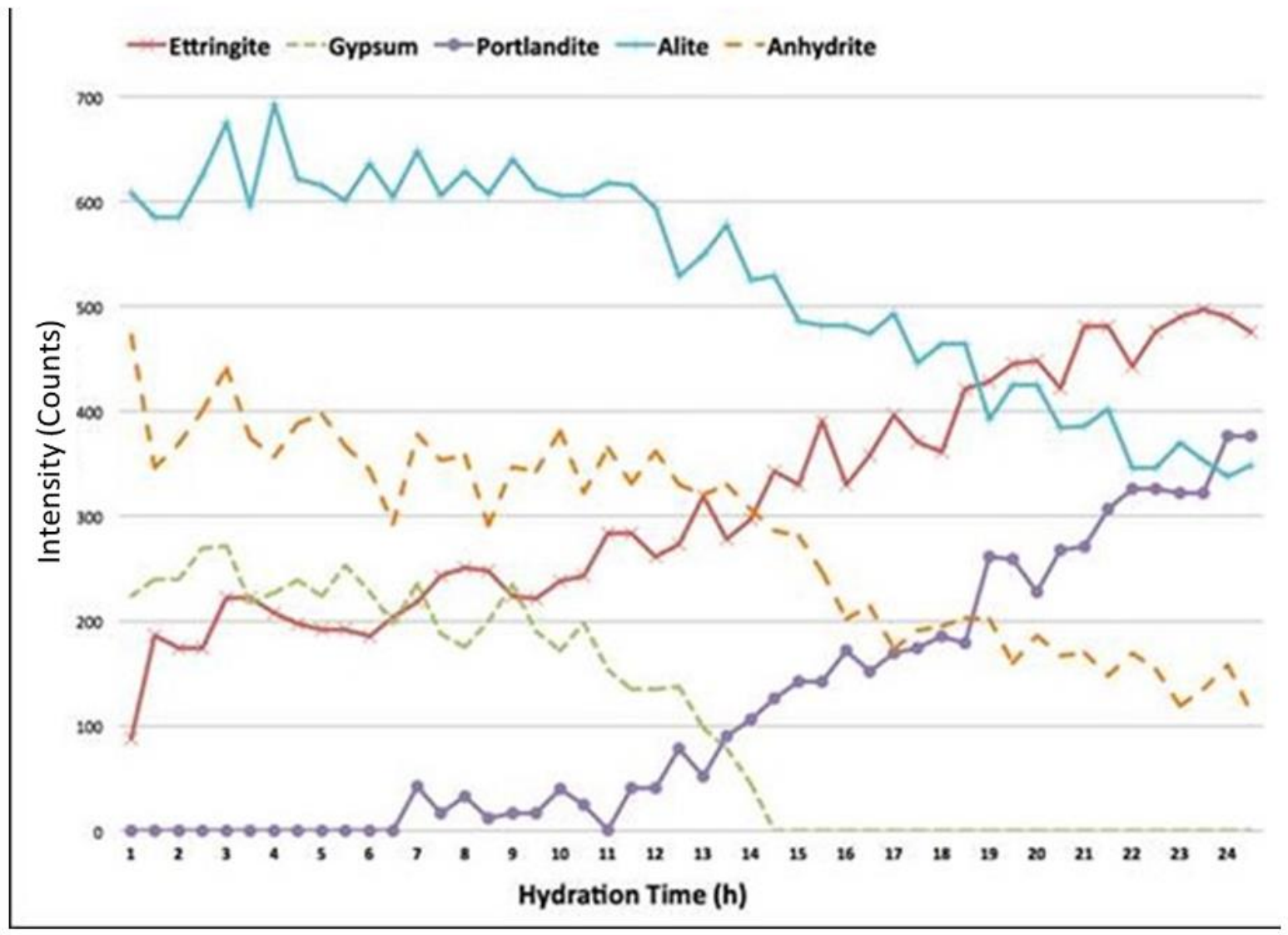

Figure 11. In situ X-ray diffraction measurement of phases present in repair mortar mixture $M-S A P$ as a function of hydration time. A measure of the uncertainty is given by the variability in the counts for alite prior to the precipitation of portlandite at $6.5 \mathrm{~h}$.

Therefore, for these repair materials, initial setting, occurring between about $2 \mathrm{~h}$ and $5 \mathrm{~h}$ (Figure 9), is actually caused by ettringite formation and not by the production of calcium silicate hydrate gel $(\mathrm{C}-\mathrm{S}-\mathrm{H})$ as in conventional ordinary portland cement-based materials. This also helps explain why retardation observed in the early-age hydration peaks corresponding to alite and renewed aluminate hydration (Figures 4 and 5) is not necessarily reflected as a delay in setting time (S-PCS and M-PCS mixtures in Figure 9). At later ages, upon total sulfate depletion, this ettringite would be expected to convert to a monosulfate (AFm) phase and it is conjectured that the dissolution of ettringite needles during this conversion could contribute to the measured autogenous shrinkage in much the same way that their formation can contribute to the measured expansion during the first few days (Bentz et al., 2001). This will be discussed further in the section on autogenous deformation to follow. 


\subsection{Fresh and mechanical properties}

The fresh and mechanical properties of the various mortar mixtures are summarized in Tables 1 and 2. Table 1 contrasts the mixtures for both material $\mathrm{S}$ and material $\mathrm{M}$ with and without IC, while Table 2 shows the properties for the three mortar mixtures prepared with a $5 \%$ replacement of repair mortar by limestone powder, in comparison to the comparable mixture without limestone powder replacement. The values for mechanical properties obtained from the manufacturer's specification sheets are also included in Table 1 for comparison purposes. Because of the additional IC water added to the mixtures with IC, their fresh density is lower than that of the comparable mixture without IC. Additional variability in fresh density would be caused by differences in the (entrapped) air content of the various mortar mixtures. Mortars prepared with material $\mathrm{M}$ generally exhibited a higher flow than those prepared with material $\mathrm{S}$ and, surprisingly, in most cases, the addition of IC to a mixture slightly decreased its flow.

The addition of IC water (and the voids left behind as the water is imbibed into the hydrating repair material paste) reduces both measured compressive strengths and elastic modulus. The strength reductions are less severe for IC via LWA, as the rigid LWA particles provide additional restraint in the developing microstructure in contrast to the non-restraining voids produced in the mixtures with PCS or SAP particles for IC. While reductions were observed with IC, mixtures S-LWA and S-PCS maintained strength levels that were superior to those listed in the manufacturer's specification sheet. Mixture M-LWA provided similar performance to the specified values, with its $1 \mathrm{~d}$ strength and $28 \mathrm{~d}$ modulus being slightly below the specification sheet values. For both materials, the ranking of strengths at the three testing ages and elastic modulus were consistently in the order of LWA > PCS > SAP.

Regarding the shear slant testing of interface bond, while the range of values for wet and dry existing (old) mortar substrates were overlapping, the specific average values measured for the dry specimens were higher than those for the wet specimens in 8 of the 10 cases (five mixtures, two ages). Conflicting results are found in the literature on this topic, but Beushausen (2015) has recently presented results for the direct shear measurement of interface bond strength that also illustrated the superiority of a dry surface over a surface-saturated (wet) one, attributing the lower bond values in the latter case to the prevention of "interlock between substrate and overlay and hence lower bond strength." The counterargument is that a dry substrate will pull water from the fresh repair material, reducing that available for hydration of the repair material in the critical location of its interface. However, removal of water from the repair mortar in its fresh state might also produce a local densification of the material (reduction in water-to-solids ratio) that will increase both strength and bond, similar to the superior interfacial transition zone often observed between LWA and their surrounding cement paste in lightweight concrete (Holm et al., 1984; Zhang and Gjorv, 1990).

Based on the limited results presented in Table 1, the mixtures with IC appear to offer similar bond performance to their non-IC counterparts for both repair materials. All specimens failed at the interface between the repair material and the existing mortar, with a portion of the specimens exhibiting a partial failure within the existing mortar (see Figure 12). Companion mortar cube tests (specimens cured under similar conditions) indicated that when tested $35 \mathrm{~d}$ after bonding, the repair materials and the existing mortar both generally exhibited a compressive 
Table 1: Fresh and mechanical properties for repair mortars with and without internal curing. Cases where the measured values were below those provided on the manufacturers' specification sheets are highlighted in either yellow ( $\leq 20 \%)$ or grey (> 20\%).

\begin{tabular}{|c|c|c|c|c|c|c|c|c|}
\hline & $\mathbf{S}$ & S-LWA & S-PCS & S-SAP & $\mathbf{M}$ & M-LWA & M-PCS & M-SAP \\
\hline Fresh density $\left(\mathrm{kg} / \mathrm{m}^{3}\right)$ & $2120 / 2150$ & $2090 / 2090$ & $2100 / 2110$ & $2060 / 2100$ & $2110 / 2210$ & $2020 / 2000$ & $2040 / 2020$ & $2030 / 2030$ \\
\hline Flow table $(\%)$ & $91 / 85$ & $77 / 79$ & $79 / 88$ & $88 / 77$ & $107 / 93$ & $88 / 85$ & $87 / 93$ & $107 / 113$ \\
\hline 1-d strength $(\mathrm{MPa})$ & $38.8(1.1 \%)^{1}$ & $36.6(2.0 \%)$ & $32.2(5.6 \%)$ & $13.5(4.6 \%)$ & $28.6(1.3 \%)$ & $19.2(6.3 \%)$ & $13.0(10 \%)$ & $12.9(7.1 \%)$ \\
\hline 7-d strength (MPa) & $69.9(5.9 \%)$ & $70.3(1.3 \%)$ & $64.0(1.0 \%)$ & $46.7(4.6 \%)$ & $59.9(19 \%)$ & $52.0(3.7 \%)$ & $42.7(7.4 \%)$ & $42.8(2.2 \%)$ \\
\hline 28-d strength (MPa) & $89.8(6.6 \%)$ & $84.6(5.2 \%)$ & $80.2(6.2 \%)$ & $62.7(8.3 \%)$ & $90.8(5.6 \%)$ & $73.6(2.5 \%)$ & $59.0(3.3 \%)$ & $52.8(4.0 \%)$ \\
\hline $28+-\mathrm{d}$ modulus $(\mathrm{GPa})$ & $36.8(6.0 \%)$ & $33.7(3.4 \%)$ & $30.3(2.6 \%)$ & $28.8(2.8 \%)$ & $34.4(5.5 \%)$ & $31.6(19 \%)$ & $29.3(4.8 \%)$ & $27.7(2.0 \%)$ \\
\hline $\begin{array}{c}7 \text { d slant (MPa) } \\
\text { wet/dry }\end{array}$ & $\begin{array}{c}{[16.9 / 16.5]^{2}} \\
21.6 / 23.9^{3}\end{array}$ & $16.8 / 19.5$ & $18.1 / 19.4$ & $\begin{array}{c}\text { Not } \\
\text { tested }\end{array}$ & $20.2 / 23.3$ & $21.7 / 24.3$ & $\begin{array}{c}\text { Not } \\
\text { tested }\end{array}$ & $\begin{array}{c}\text { Not } \\
\text { tested }\end{array}$ \\
\hline $\begin{array}{c}35 \mathrm{~d} \text { slant }(\mathrm{MPa}) \\
\text { wet/dry }\end{array}$ & $\begin{array}{c}{[21.4 / 22.5]^{2}} \\
25.6 / 26.3\end{array}$ & $24.1 / 19.3$ & $19.0 / 20.1$ & $\begin{array}{c}\text { Not } \\
\text { tested }\end{array}$ & $25.5 / 30.9$ & $31.3 / 28.5$ & $\begin{array}{c}\text { Not } \\
\text { tested }\end{array}$ & $\begin{array}{c}\text { Not } \\
\text { tested }\end{array}$ \\
\hline \multicolumn{9}{|c|}{ Manufacturers' Specification Sheet Values } \\
\hline 1-d strength $(\mathrm{MPa})$ & \multicolumn{4}{|c|}{31} & \multicolumn{4}{|c|}{24.1} \\
\hline 7-d strength & \multicolumn{4}{|c|}{55} & \multicolumn{4}{|c|}{45.5} \\
\hline 28-d strength & \multicolumn{4}{|c|}{69} & \multicolumn{4}{|c|}{62.1} \\
\hline 28-d modulus (GPa) & \multirow{3}{*}{\multicolumn{4}{|c|}{$>241$}} & \multicolumn{4}{|c|}{34.5} \\
\hline 7 d slant $(\mathrm{MPa})$ & & & & & \multicolumn{4}{|c|}{17.2} \\
\hline $28 \mathrm{~d}$ slant $(\mathrm{MPa})$ & & & & & \multicolumn{4}{|c|}{20.7} \\
\hline
\end{tabular}

${ }^{1}$ Percentages in parentheses indicate coefficient of variation for three replicate specimens.

${ }^{2}$ Numbers in brackets indicate values when existing mortar half specimens were not rinsed with tap water following removal from lime-water storage solution.

${ }^{3}$ Typical coefficients of variation for the shear slant specimens were on the order of $10 \%$ for either two or three replicate specimens.

Table 2: Fresh and mechanical properties for repair mortars with limestone powder replacements in comparison to comparable mixtures without limestone.

\begin{tabular}{|c|c|c|c|c|c|}
\hline & S-LWA & S-LWA-cLSP & M & M-fLSP & M-cLSP \\
\hline Fresh density $\left(\mathrm{kg} / \mathrm{m}^{3}\right)$ & $2090 / 2090$ & $2100 / 2090$ & $2110 / 2210$ & $2080 / 2080$ & $2090 / 2100$ \\
\hline Flow table $(\%)$ & $77 / 79$ & $71 / 84$ & $107 / 93$ & $101 / 99$ & $107 / 108$ \\
\hline 1-d strength $(\mathrm{MPa})$ & $36.6(2.0 \%)$ & $33.6(8.5 \%)$ & $28.6(1.3 \%)$ & $22.9(1.2 \%)$ & $18.4(2.5 \%)$ \\
\hline 7-d strength $(\mathrm{MPa})$ & $70.3(1.3 \%)$ & $66.6(5.2 \%)$ & $59.9(19 \%)$ & $54.9(3.7 \%)$ & $53.4(4.1 \%)$ \\
\hline 28-d strength $(\mathrm{MPa})$ & $84.6(5.2 \%)$ & $88.4(9.6 \%)$ & $90.8(5.6 \%)$ & $74.7(7.6 \%)$ & $77.9(5.0 \%)$ \\
\hline 28+-d modulus $(\mathrm{GPa})$ & $33.7(3.4 \%)$ & $30.4(3.7 \%)$ & $34.4(5.5 \%)$ & $33.0(1.9 \%)$ & $33.6(3.8 \%)$ \\
\hline
\end{tabular}


strength on the order of $75 \mathrm{MPa}$ to $80 \mathrm{MPa}$. The importance of surface cleanliness prior to the application of the repair material is shown in Table 1, where the bond strengths for the material $S$ specimens that were not rinsed following their removal from the lime-water (leaving behind deposits of lime and other residues) exhibited a bond strength about $20 \%$ lower than that measured for comparable rinsed specimens.
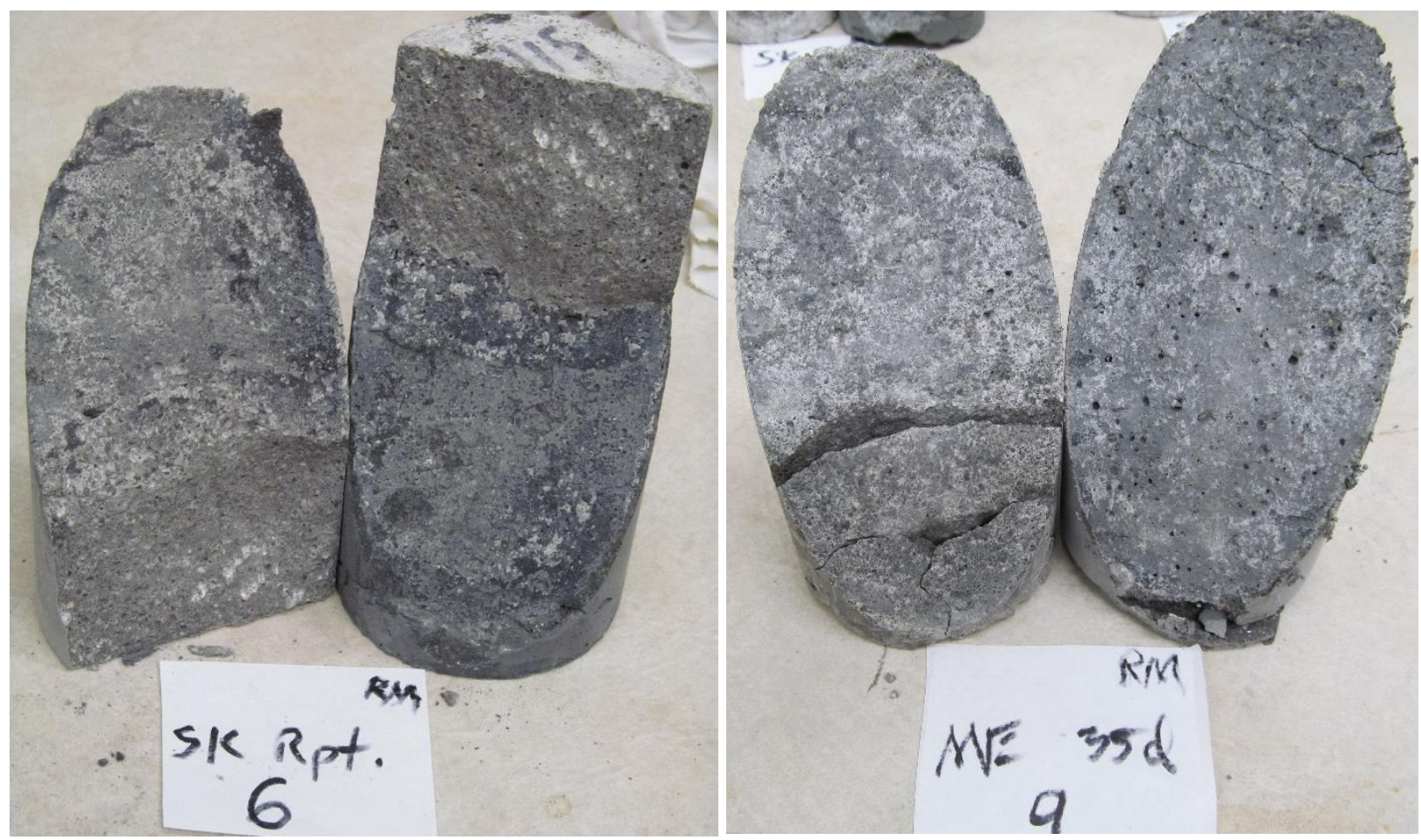

Figure 12. Photos of typical specimens after shear slant testing. Some strong bonding of the two materials is indicated by the deposits of one material on the opposing material face. The (darker) repair material half specimen is on the right in both images.

Based on the values in Table 2, the replacement of repair material $\mathrm{M}$ with limestone powder generally reduced the mechanical properties, likely due to dilution of the reactive component concentration. This was especially true for the $1 \mathrm{~d}$ strengths for these mixtures. In contrast, the properties of S-LWA and S-LWA-cLSP were fairly similar, with both exceeding the manufacturer's specified values. 


\subsection{Autogenous deformation}

The autogenous deformation measurements for mortars based on materials $\mathrm{S}$ and $\mathrm{M}$ are summarized in Figure 13 and Figure 14, respectively. The presented measurements were initiated at a time zero corresponding to the final setting time of each mortar mixture (varying between $5 \mathrm{~h}$ and $8 \mathrm{~h}$ ), as determined using the needle penetration (Figure 9, taking final set as being $3 \mathrm{~h}$ beyond the indicated initial set time) and isothermal calorimetry (Figures 4 and 5) results. The two materials without IC exhibit $28 \mathrm{~d}$ shrinkages of about 350 microstrain and 500 microstrain, which could be sufficient to initiate early-age cracking under field conditions. Material S first exhibits a small expansion for about $1 \mathrm{~d}$, followed by monotonic shrinkage, while material $\mathrm{M}$ shrinks from the time of final setting throughout the $28 \mathrm{~d}$ measurement period. The autogenous deformation measured in these materials is a competition between autogenous shrinkage produced by the chemical shrinkage that accompanies the hydration reactions and expansion that is produced by the formation of ettringite needles and perhaps other expansive agents added to the mortar formulation (Bentz et al., 2001; Bentz and Jensen, 2004).

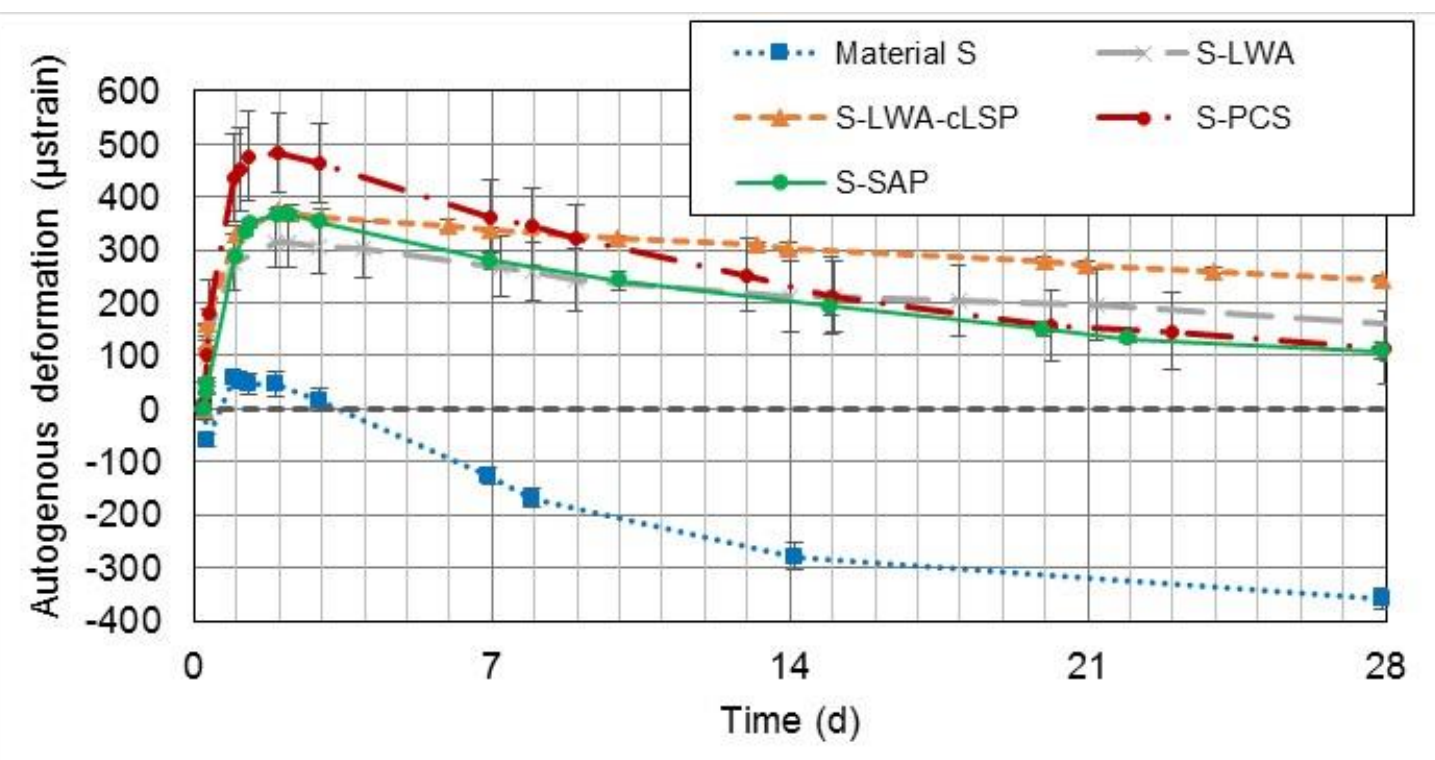

Figure 13. Measured autogenous deformation for repair mortar mixtures based on material S. Error bars indicate \pm one standard deviation for three replicate specimens.

Internal curing, using any of the investigated IC agents, significantly reduces, but doesn't eliminate, the measured autogenous shrinkage, particularly when shrinkage subsequent to the peak expansion is considered. As water from the IC agent maintains saturation of the paste, autogenous shrinkage due to self-desiccation is minimized and more of the true expansion of the paste due to its expansive phases can be seen. This expansion dominates the deformation for the first $2 \mathrm{~d}$ to 3 $\mathrm{d}$ for the two repair materials investigated in this study. However, shrinkage is observed beyond this time, even though IC should be maintaining a saturated paste and self-desiccation should remain minimal. It is conjectured that a large portion of this subsequent shrinkage is due to the dissolution of restraining ettringite needles (and perhaps calcium hydroxide crystals), as following calcium sulfate (gypsum and anhydrite in Figures 10 and 11) depletion, subsequent ettringite dissolution can enrich the solution with enough sulfate to trigger precipitation of 
monosulfoaluminate (one of several phases designated as "AFm"). This is consistent with the observation that the systems in which more expansion has occurred (S-PCS and M-PCS) exhibit more shrinkage afterward, relative to the peak expansion value. The mortars with a lower modulus also exhibit a greater expansion and subsequent shrinkage, consistent with a relatively fixed stress being converted to a higher strain in a lower modulus material. One possibility for reducing this subsequent shrinkage would be to attempt to stabilize the ettringite and other expansive products that are formed by the incorporation of additional calcium sulfate or possibly a source of calcium carbonate (limestone) into the mortar formulation. The former would potentially consume all of the aluminate phases while maintaining a slight sulfate surplus, thereby preventing the conversion of ettringite. The latter favors the formation of carboaluminate phases (monocarboaluminate and hemicarboaluminate) over the AFm phase, also stabilizing the ettringite formed at early ages in the process (Lothenbach et al., 2008; Zajac et al., 2014). The latter approach was the one investigated in the present study via the three additional mortar mixtures that replaced $5 \%$ of the repair mortar (dry product) with either a fine or coarse limestone powder.

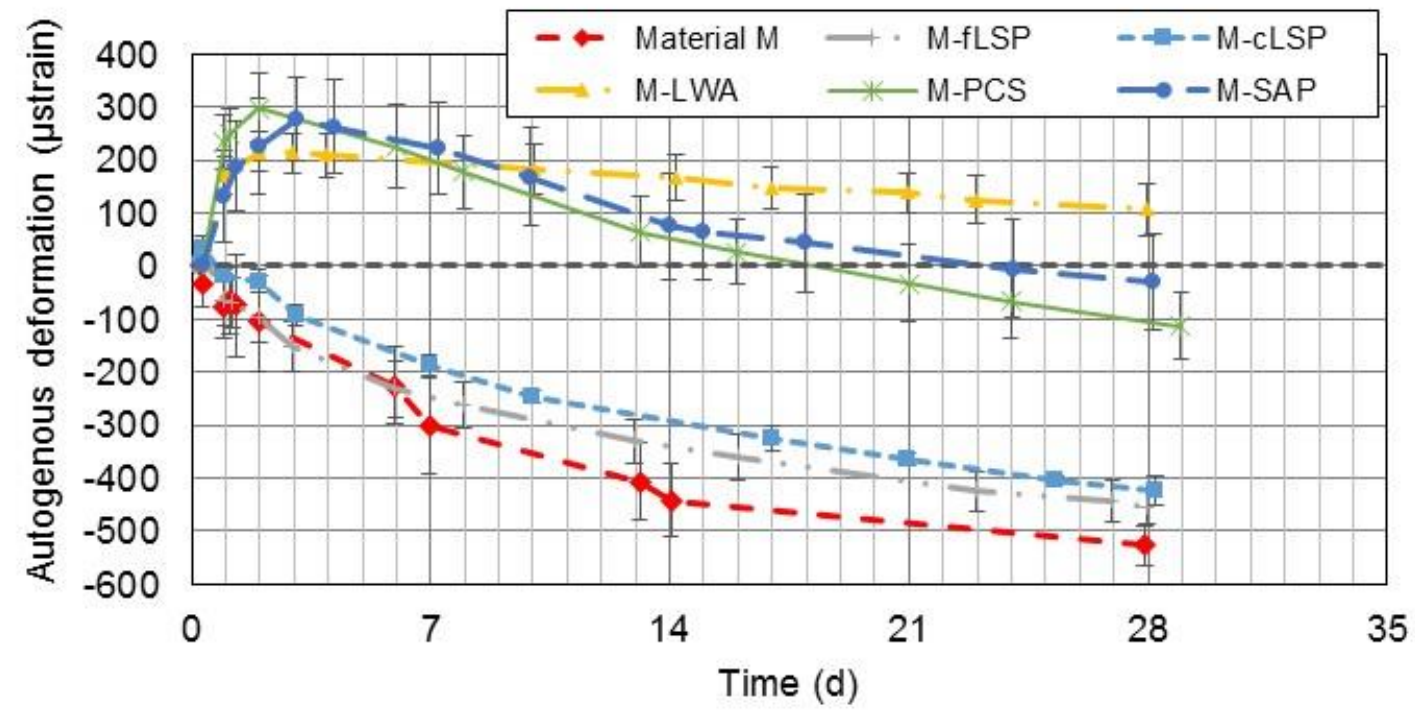

Figure 14. Measured autogenous deformation for repair mortar mixtures based on material M. Error bars indicate \pm one standard deviation for three replicate specimens.

Cusson (2008) has suggested that it is not only the measured long term autogenous deformation that is a critical performance measure for early-age cracking, but also the deformation path that has been taken. Thus, he advocates characterizing the autogenous shrinkage by the difference between the maximum measured expansion at early ages (or 0 if no expansion is observed) and the value subsequently obtained at an age of $7 \mathrm{~d}$. The efficacy of an IC agent can then be assessed as the relative reduction in this quantity with respect to that measured on a corresponding system without IC. In the present study, this analysis of Cusson was conducted for ages of $7 \mathrm{~d}$ and $28 \mathrm{~d}$ and the obtained results are presented in Table 3. For these two repair materials, IC provided by LWA is more effective than that provided by PCS or SAP, particularly at the age of $28 \mathrm{~d}$. While the less stiff PCS and SAP particles allow significantly more expansion during the first day, they subsequently also allow more shrinkage when this expansion ceases and some of the restraining particles, such as ettringite needles, dissolve. Conversely, the mortars with 
LWA exhibit a higher modulus (Table 1) to better resist deformation and the rigid and more voluminous LWA particles will also provide additional restraint, while the shrinking mortar phase is reduced to occupying only $82 \%$ of the overall system volume in the mortars formulated with LWA for IC (Figure 2), versus about $95 \%$ in those with SAP or PCS for IC.

Relative to the effectiveness of IC, the replacement of $5 \%$ of the repair material with limestone powder provides little improvement in autogenous shrinkage reduction. In material $\mathrm{M}$ without IC, the measured shrinkage is due to both self-desiccation and dissolution of expansive phases and the limestone replacement will only potentially mitigate the latter, while it seems that the former is accounting for $80 \%$ to $90 \%$ of the total shrinkage. In the mortars based on material $\mathrm{M}$ with limestone powder replacement, a coarser limestone powder is more effective in reducing autogenous shrinkage than a finer one, likely due to the increased interparticle spacing that it creates, as has been observed previously in portland cement-based systems (Bentz and Peltz, 2008). The combination of IC with LWA and the incorporation of the coarse limestone into material S produced IC efficiencies of $82 \%$ at $7 \mathrm{~d}$ and $70 \%$ at $28 \mathrm{~d}$ in contrast to efficiencies of $74 \%$ and $63 \%$ at the same two ages for mortar S-LWA, indicating the potential utility of such a combination of mitigation strategies in nearly eliminating autogenous shrinkage. In the case of S-LWA-cLSP, the remaining shrinkage could be due to either a slight under dosage of the IC water, the stabilization of only a portion of the ettringite by the limestone powder replacement, or the dissolution of other microstructural features such as calcium hydroxide crystals, the latter process being expected to be a prominent contribution in repair materials containing pozzolans such as fly ash and/or silica fume. According to its manufacturer, material S does indeed contain silica fume.

Table 3: Post-peak to 7 d or 28 d autogenous shrinkage of repair mortar mixtures with and without internal curing as per Cusson (2008).

\begin{tabular}{|c|c|c|c|c|}
\hline Mixture & $\begin{array}{c}\text { Peak-7 d } \\
\text { shrinkage } \\
\text { (microstrain) }\end{array}$ & $\begin{array}{c}\text { IC efficiency - } \\
\text { Reduction vs. } \\
\text { control without } \\
\text { IC (7 d) }\end{array}$ & $\begin{array}{c}\text { Peak-28 d } \\
\text { shrinkage } \\
\text { (microstrain) }\end{array}$ & $\begin{array}{c}\text { IC efficiency - } \\
\text { Reduction vs. } \\
\text { control without } \\
\text { IC (28 d) }\end{array}$ \\
\hline Material S & 186 & & 420 & \\
\hline Material M & 301 & & 526 & $63 \%$ \\
\hline S-LWA & 48 & $74 \%$ & 155 & $79 \%$ \\
\hline M-LWA & 20 & $94 \%$ & 109 & $12 \%$ \\
\hline S-PCS & 121 & $35 \%$ & 368 & $22 \%$ \\
\hline M-PCS & 98 & $68 \%$ & 411 & $38 \%$ \\
\hline S-SAP & 87 & $53 \%$ & 259 & $42 \%$ \\
\hline M-SAP & 54 & $82 \%$ & 306 & $70 \%$ \\
\hline S-LWA-cLSP & 34 & $82 \%$ & 127 & $7 \%$ \\
\hline M-fLSP & 282 & $6 \%$ & 489 & $13 \%$ \\
\hline M-cLSP & 221 & $27 \%$ & 458 & \\
\hline
\end{tabular}




\subsection{Drying shrinkage}

The drying shrinkage measured on eight of the repair mortars during the course of $28 \mathrm{~d}$ is shown in Figure 15, while the ultimate drying shrinkage determined from the analysis outlined in ASTM C596 (ASTM International, 2009) is provided in Table 4. While IC generally reduced the drying shrinkage measured during the first few weeks of drying exposure, the ultimate drying shrinkage calculated according to the ASTM C596 standard was slightly increased in the systems with PSC or SAP as the IC agent. This increase is likely partially due to the reduced modulus of these materials (Table 1). The ultimate drying shrinkage for the systems with SAP is slightly higher than that for the corresponding system with PCS for both repair materials, once again consistent with their lower modulus. As shown in Table 4, the replacement of either repair material by limestone powder at a $5 \%$ level did not significantly alter their projected ultimate drying shrinkage.
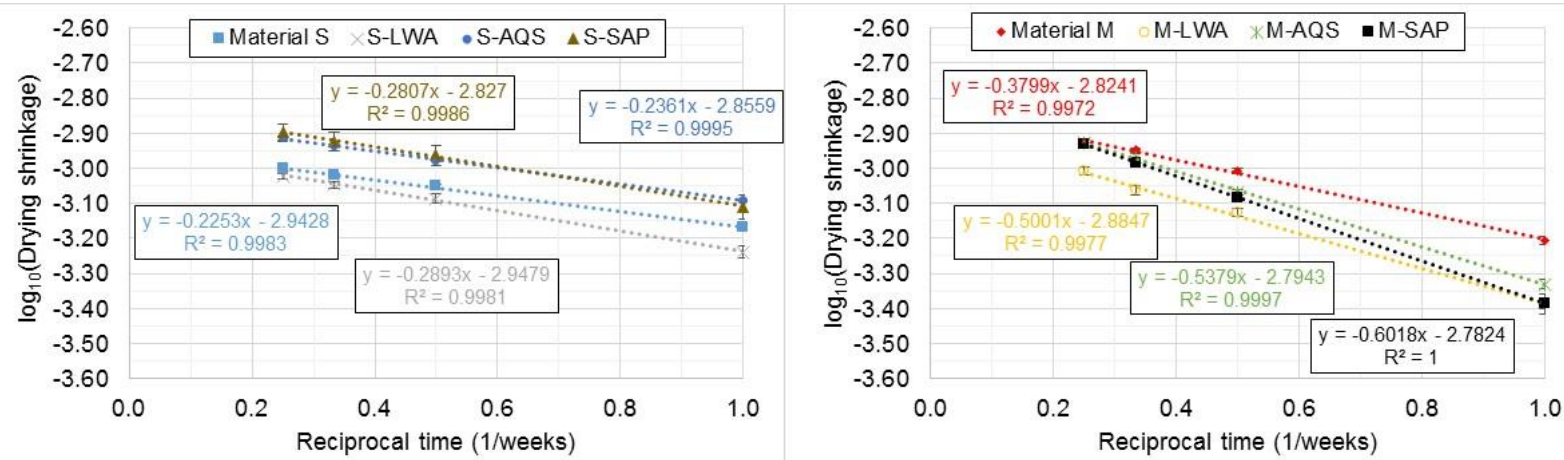

Figure 15. Measured (log) drying shrinkage vs. reciprocal time for the mortars based on materials $S$ (left) and $M$ (right). Errors bar indicate \pm one standard deviation for six replicate specimens.

Table 4: Ultimate drying shrinkage estimated for the repair mortar mixtures with and without internal curing.

\begin{tabular}{|c|c|}
\hline Mixture & Ultimate drying shrinkage (\%) \\
\hline Material S & $0.11 \%$ \\
\hline S-LWA & $0.11 \%$ \\
\hline S-LWA-cLSP & $0.12 \%$ \\
\hline S-PCS & $0.14 \%$ \\
\hline S-SAP & $0.15 \%$ \\
\hline Material M & $0.15 \%$ \\
\hline M-fLSP & $0.15 \%$ \\
\hline M-cLSP & $0.15 \%$ \\
\hline M-LWA & $0.13 \%$ \\
\hline M-PCS & $0.16 \%$ \\
\hline M-SAP & $0.17 \%$ \\
\hline
\end{tabular}

The drying shrinkage for eight of the mortar mixtures is plotted against measured mass loss in Figure 16. A highly linear relationship $\left(\mathrm{R}^{2}>0.98\right)$ is observed for each mortar mixture. A portion 
of the additional IC water available in the mortars with IC is removed during drying, producing higher mass losses in those samples at each measurement time. However, this additional water loss doesn't produce increased shrinkage as the IC water is contained in pores (within LWA, surrounding the PCS particle core, or constituting the expanded SAP particle) that are much larger than those in the hydrating paste microstructure. Thus, their emptying doesn't introduce any substantial stress (or shrinkage) on the hardened mortar microstructure. This also helps explain why the initial shrinkage measured in the mortars with IC can be less than that in the corresponding mortar without IC (see material $\mathrm{M}$ for example), namely due to the emptying of the larger IC pores instead of the smaller pores in the hydrating paste microstructure. Ultimately, upon prolonged exposure to a fixed RH environment, similarly sized pores within the hydrating paste will empty in each mortar and the IC mortars will have a possibly increased ultimate drying shrinkage based on their (reduced) modulus.
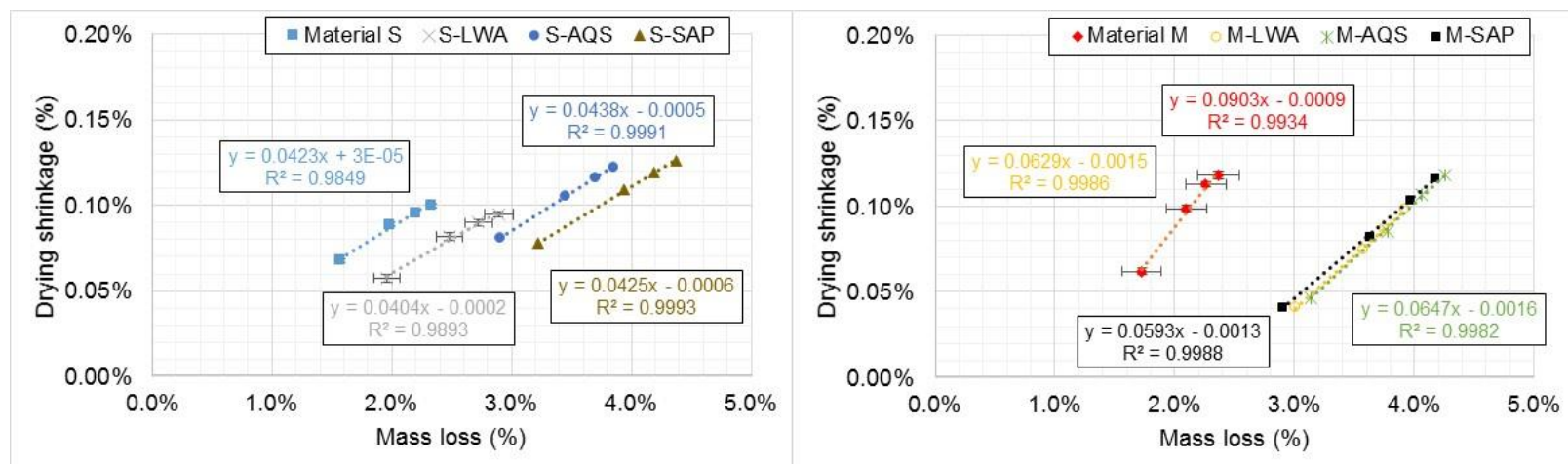

Figure 16. Measured drying shrinkage vs. measured mass loss for the mortars based on materials $S$ (left) and $M$ (right). Errors bar indicate \pm one standard deviation for six replicate specimens. 


\section{Conclusions}

The main objective of the present study was to investigate strategies for reducing autogenous shrinkage of cement-based repair materials. In the context of evaluating two representative repair materials, the following conclusions were drawn:

- IC can be provided by a variety of agents, with their water capacities (per unit mass) differing by up to two orders of magnitude, but their water capacity will influence the mixture proportioning and performance of the resulting mortar,

- IC, provided via LWA, PCS, or SAP provided a significant reduction in the measured autogenous deformation of both repair materials,

- the addition of an IC agent produced a retardation of the hydration reactions (particularly in the cases of the PCS and SAP), reduced compressive strengths, a reduced elastic modulus, and a slightly increased ultimate drying shrinkage, the latter in the cases of PCS and SAP only,

- of the three IC agents investigated in this study, LWA produced the highest compressive strengths (and modulus) and an equivalent or slightly reduced ultimate drying shrinkage in comparison to the corresponding repair material without IC, and exhibited the greatest efficiency in reducing autogenous shrinkage,

- based on quantitative X-ray diffraction analysis, both repair materials produce a substantial quantity of ettringite upon contact with water, which is responsible for their initial setting, unlike conventional portland cement-based materials in which the formation of $\mathrm{C}-\mathrm{S}-\mathrm{H}$ is chiefly responsible for percolation and setting,

- it is conjectured that a portion of this early-age ettringite dissolves upon sulfate (gypsum and anhydrite) depletion in the material, removing restraining needles (crystals) and contributing to the measured autogenous shrinkage in systems without and even with IC,

- the replacement of $5 \%$ of the dry repair material with a coarse limestone powder provides a reduction in autogenous shrinkage in systems without IC and a further reduction in autogenous shrinkage in systems with IC, likely by stabilizing a portion of the early-age ettringite, as carboaluminate formation is favored over that of sulfoaluminates; the changes in other properties due to the incorporation of coarse limestone powder into the S-LWA mortar were minimal.

Further research on the later age transition of the ettringite to monosulfoaluminate phases in these repair materials and its impact on performance properties including bond strength would be valuable. This topic is currently being investigated in collaboration with the Federal Highway Administration Turner-Fairbanks Highway Research Center (FHWA-TFHRC) and NIST. 


\section{Acknowledgements}

The authors would like to thank Aquasmart Enterprises, LLC, Koda, Lehigh Cement Company, Northeast Solite Corporation, OMYA Inc., and Sika Corporation for supplying materials utilized in the present study. The assistance of Prof. Tyler Ley of Oklahoma State University and Dr. Edward Garboczi of NIST/Boulder in supplying X-ray microtomography data sets of the repair mortars with SAP is gratefully acknowledged. The authors also thank Dr. Jeffrey Bullard of the Engineering Laboratory at NIST for the suggestion of using limestone additions to further reduce the autogenous shrinkage of the repair mortars and for his assistance, along with Dr. Pan Feng, in measuring the absorption of calcium ions by the IC agents using inductively coupled plasma (ICP) analysis. Useful discussions with Dr. Igor de la Varga and Dr. José Munoz of the FHWA-TFHRC are gratefully acknowledged. 


\section{References}

American Society for Civil Engineers. (2013). http://www.infrastructurereportcard.org/grades/, accessed March 27, 2015.

ASTM International. (2009). ASTM C596-09 Standard Test Method for Drying Shrinkage of Mortar Containing Hydraulic Cement. West Conshohocken: ASTM International.

ASTM International. (2012a). ASTM C150/C150M-12 Standard Specification for Portland Cement. West Conshohocken: ASTM International.

ASTM International. (2012b). ASTM C1608-12 Standard Test Method for Chemical Shrinkage of Hydraulic Cement Paste. West Conshohocken: ASTM International.

ASTM International. (2013a). ASTM C1437-13 Standard Test Method for Flow of Hydraulic Cement Mortar. West Conshohocken: ASTM International.

ASTM International. (2013b). ASTM C109/C109M-13 Standard Test Method for Compressive Strength of Hydraulic Cement Mortars. West Conshohocken: ASTM International.

ASTM International. (2013c). ASTM C882/C882M-13a Standard Test Method for Bond Strength of Epoxy-Resin Systems Used with Concrete by Slant Shear. West Conshohocken: ASTM International.

ASTM International. (2013d). ASTM C1761/C1761M-13b Standard Specification for Lightweight Aggregate for Internal Curing of Concrete. West Conshohocken: ASTM International.

ASTM International. (2013e). ASTM C191-13 Standard Test Methods for Time of Setting of Hydraulic Cement by Vicat Needle. West Conshohocken: ASTM International.

ASTM International (2014a). ASTM C305-14 Standard Practice for Mechanical Mixing of Hydraulic Cement Pastes and Mortars of Plastic Consistency. West Conshohocken: ASTM International.

ASTM International. (2014b). ASTM C1698-09(2014) Standard Test Method for Autogenous Strain of Cement Paste and Mortar. West Conshohocken: ASTM International.

ASTM International. (2014c). ASTM C1259-14 Standard Test Method for Dynamic Young's Modulus, Shear Modulus, and Poisson's Ratio for Advanced Ceramics by Impulse Excitation of Vibration. West Conshohocken: ASTM International.

ASTM International (2015). ASTM C185-15 Standard Test Method for Air Content of Hydraulic Cement Mortar. West Conshohocken: ASTM International. 
Bentz, D., Jensen, O., Hansen, K., Olesen, J., Stang, H., and Haecker, C. (2001). Influence of Cement Particle Size Distribution on Early Age Autogenous Strains and Stresses in Cement-Based Materials. Journal of the American Ceramic Society, 84 (1), 129-135.

Bentz, D.P., \& Jensen, O.M. (2004). Mitigation Strategies for Autogenous Shrinkage Cracking. Cement and Concrete Composites, 26 (6), 677-685.

Bentz, D., Lura, P., \& Roberts, J. (2005). Mixture Proportioning for Internal Curing. Concrete International, 27 (2), 35-40.

Bentz, D., \& Turpin, R. (2007). Potential Applications of Phase Change Materials in Concrete Technology. Cement and Concrete Composites, 29, 527-532.

Bentz, D., \& Peltz, M. (2008). Reducing Thermal and Autogenous Shrinkage Contributions to Early-Age Cracking. ACI Materials Journal, 105 (4), 414-420.

Bentz, D., \& Weiss, J. (2011). Internal Curing: A 2010 State-of-the-Art Review. NISTIR 7765, U.S. Department of Commerce, February.

Bentz, D., Ardani, A., Barrett, T., Jones, S., Lootens, D., Peltz, M., Sato, T., Stutzman, P., Tanesi, J., and Weiss, W. (2014). Multi-Scale Investigation of the Performance of Limestone in Concrete. Construction and Building Materials, 75, 1-10.

Bentz, D., Jones, S., and Snyder, K. (2015). Design and Performance of Ternary Blend HighVolume Fly Ash Concretes of Moderate Slump. Construction and Building Materials, 84, 409-415.

Beushausen, H. (2015). The Influence of Precast Surface Moisture Condition on Overlay Bond Strength. Concrete Plant International, 1|2015, 144-147.

Beushausen, H., and Gillmer, M. (2014). The Use of Superabsorbent Polymers to Reduce Cracking of Bonded Mortar Overlays. Cement and Concrete Composites, 52, 1-8.

Cusson, D. (2008). Effect of Blended Cements on Efficiency of Internal Curing of HPC. in ACI SP-256, Internal Curing of High-Performance Concretes: Laboratory and Field Experiences, D. Bentz and B. Mohr, Eds., American Concrete Institute, Farmington Hills, MI, 105-120.

De la Varga, I., \& Graybeal, B. (2014). Dimensional Stability of Grout-Type Materials Used as Connections between Prefabricated Concrete Elements. ASCE Journal of Materials in Civil Engineering, 10.1061/(ASCE)MT.1943-5533.0001212.

Gurney, L., Bentz, D., Sato, T., and Weiss, J. (2012). Reducing Set Retardation in High Volume Fly Ash Mixtures with the Use of Limestone: Improving Constructability for Sustainability. Transportation Research Record, Journal of the Transportation Research Board, No. 2290, Concrete Materials 2012, 139-146. 
Holm, T., Bremner, T., \& Newman, J. (1984). Lightweight Concrete Subject to Severe Weathering. Concrete International, 6, 49-54.

Lothenbach, B., Le Saout, G., Gallucci, E., \& Scrivener, K. (2008). Influence of Limestone on the Hydration of Portland Cements. Cement and Concrete Research, 38, 848-860.

Morgan, D.R. (1996). Compatibility of Concrete Repair Materials and Systems. Construction and Building Materials, 10 (1), 57-67.

Weiss, W.J., Bentz, D.P., \& DiBella, C. (2013). Improving Concrete Bridge Decks with Internal Curing. Concrete Bridge Views, Issue 69, Portland Cement Association, Jan/Feb.

Zajac, M., Rossberg, A., Le Saout, G., \& Lothenbach, B. (2014). Influence of Limestone and Anhydrite on the Hydration of Portland Cements. Cement and Concrete Composites, 46, 99-108.

Zhang, M., \& Gjorv, O. (1990). Microstructure of the Interfacial Zone between Lightweight Aggregate and Cement Paste. Cement and Concrete Research, 20, 610-618. 